\title{
Adapting parent -child interaction therapy to train Head Start teachers in behavior management
}

\author{
Alisa B. Bahl \\ West Virginia University
}

Follow this and additional works at: https://researchrepository.wvu.edu/etd

\section{Recommended Citation}

Bahl, Alisa B., "Adapting parent -child interaction therapy to train Head Start teachers in behavior management" (2000). Graduate Theses, Dissertations, and Problem Reports. 1194.

https://researchrepository.wvu.edu/etd/1194

This Dissertation is protected by copyright and/or related rights. It has been brought to you by the The Research Repository @ WVU with permission from the rights-holder(s). You are free to use this Dissertation in any way that is permitted by the copyright and related rights legislation that applies to your use. For other uses you must obtain permission from the rights-holder(s) directly, unless additional rights are indicated by a Creative Commons license in the record and/ or on the work itself. This Dissertation has been accepted for inclusion in WVU Graduate Theses, Dissertations, and Problem Reports collection by an authorized administrator of The Research Repository @ WVU.

For more information, please contact researchrepository@mail.wvu.edu. 
Adapting Parent-Child Interaction Therapy to Train Head Start Teachers in Behavior Management

\author{
Alisa B. Bahl \\ Dissertation submitted to the \\ College of Arts and Sciences \\ at West Virginia University \\ in partial fulfillment of the requirements \\ for the degree of \\ Doctor of Philosophy \\ in \\ Psychology
}
Cheryl B. McNeil, Ph.D., Chair Christina D. Adams, Ph.D. Martin L. Boone, Ph.D. Robert P. Hawkins, Ph.D. Michael Perone, Ph.D.
Department of Psychology

\title{
Morgantown, West Virginia 2000
}

Keywords: Teacher training, Head Start 


\title{
ABSTRACT \\ Adapting Parent-Child Interaction Therapy to \\ Train Head Start Teachers in Behavior Management
}

\begin{abstract}
Alisa B. Bahl
Efforts toward greater inclusion of children with a range of presenting problems have resulted in increasingly more children with difficult behavior in non-specialized classrooms. Unfortunately, teachers report that they have not been trained adequately to work with children who exhibit extreme behaviors. It is important, therefore, that effective methods of training teachers are empirically investigated. In clinical settings, strategies for training parents of young children with disruptive behavior disorders have substantial empirical support. Therefore, using these techniques to train teachers is a logical step. Parent-Child Interaction Therapy is one empirically validated parent training approach that uses coaching as a means of training behavior management skills. In this study, we examined whether a 2-hour training of the skills taught in this parent training program could be used to train teachers in Head Start classrooms, and whether direct coaching resulted in greater teacher skill acquisition and child behavior change than didactic instruction alone. A multiple baseline design across classrooms was used to evaluate the effectiveness of implementing an adapted version of PCIT and the additive benefit of coaching over didactic instruction. Overall, the findings of this study did not support the effectiveness of a 2-hour training in either didactic or coaching formats for either teacher skill acquisition or child behavior change. Directions for future research are suggested.
\end{abstract}




\section{Acknowledgments}

I would like to thank the Monongalia County Head Start teachers and administrators who dedicated their time and commitment to this project. Participating teachers were Christine Anderson, Christina Hatch, Becky Davis, Bonnie Wandel, Ruth Siegel, and Darlene Rudash. Administrators who helped facilitate this research were Cheryl Winke and Joanne Martin.

I would like to recognize my chair, Cheryl McNeil, and my committee members, Christina Adams, Martin Boone, Robert Hawkins, Donald Kincaid, and Michael Perone. This project could not have been completed without their support and assistance. Also, this project could not have been completed without the participation of several research assistants who committed their time. These individuals include Karla Anhalt, Tracy Berry, Kristen Mumaw, Lisa Rizzuto, Patrick Stanislazyck, Angela Starcher, and Jennifer Vincent.

Also, I thank my parents for supporting me in this project, as well as the many others that brought me to this point over the past 5 years. Finally, I never would have completed this project without the consistent encouragement and support from Ethan Long.

This research was funded in part by the Department of Psychology Alumni Fund and Office of Academic Affairs at West Virginia University. 


\section{Table of Contents}

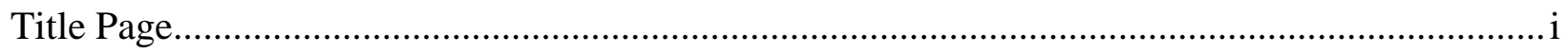

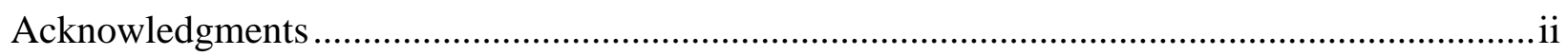

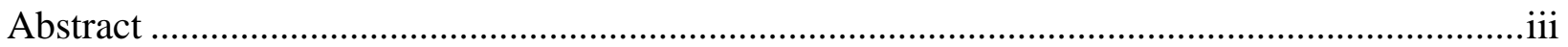

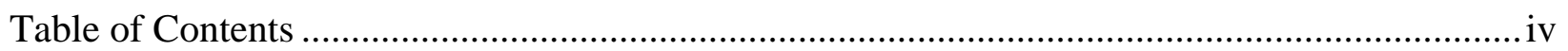

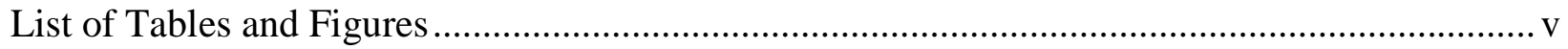

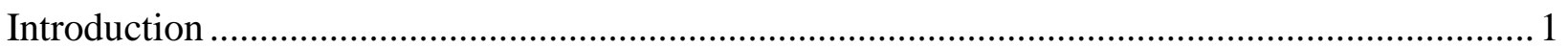

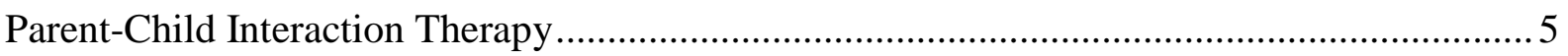

Adapting Parent-Child Interaction Therapy to the Classroom ............................................ 8

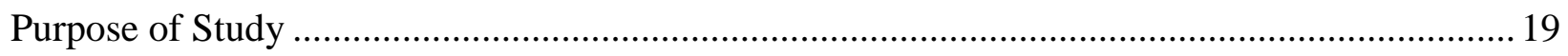

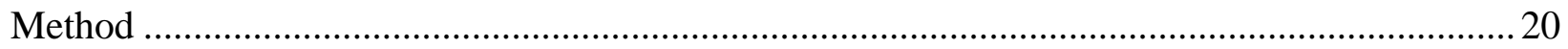

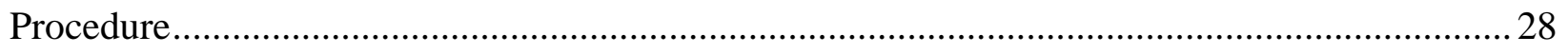

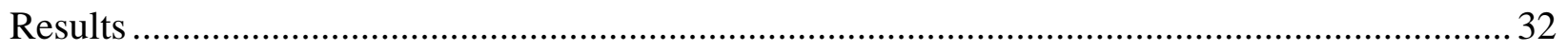

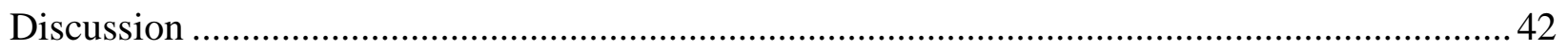

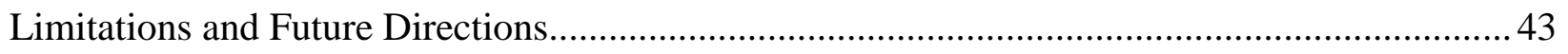

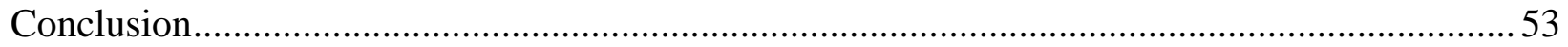

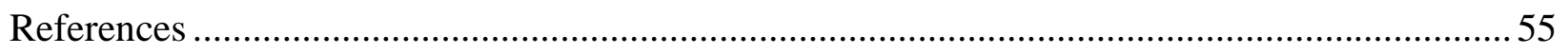

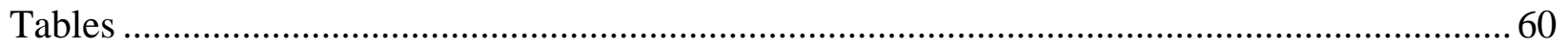

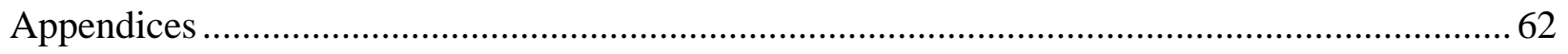

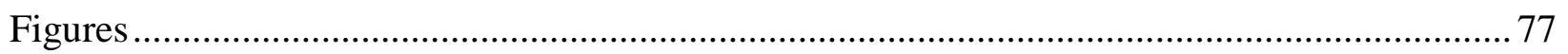




\section{List of Tables and Figures}

\section{$\underline{\text { Tables }}$}

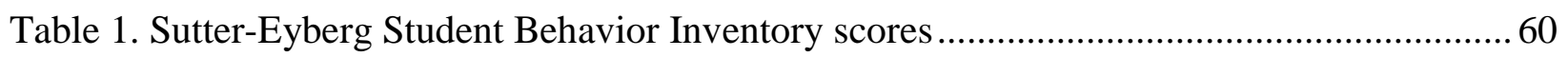

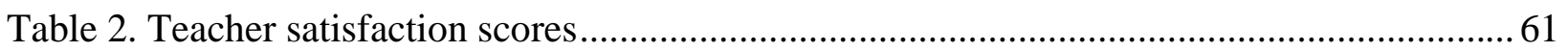

\section{$\underline{\text { Figures }}$}

Figure 1. Percent of appropriate child behavior.

Figure 2. Frequency of descriptive/reflective statements, praise, criticism, and questions

for Teacher 1

Figure 3. Frequency of descriptive/reflective statements, praise, criticism, and questions

for Teacher 2

Figure 4. Percent of direct commands for Teachers 1 and 2.

Figure 5.Frequency of descriptive/reflective statements, praise, criticism, and questions

for Teacher 3

Figure 6. Frequency of descriptive/reflective statements, praise, criticism, and questions

for Teacher 4

Figure 7. Percent of direct commands for Teachers 3 and 4.

Figure 8. Frequency of descriptive/reflective statements, praise, criticism, and questions

for Teacher 5

Figure 9. Frequency of descriptive/reflective statements, praise, criticism, and questions

for Teacher 6

Figure 10. Percent of direct commands for Teachers 5 and 6 86 


\section{Adapting Parent-Child Interaction Therapy to \\ Train Head Start Teachers in Behavior Management}

One of the biggest concerns facing teachers today is the management of disruptive classroom behavior. In fact, efforts toward greater inclusion of children with a range of presenting problems have resulted in increasingly more children with difficult behavior in nonspecialized classrooms. Unfortunately, teachers report that they have not been trained adequately to work with children who exhibit extreme behaviors (Brandenberg, Freidman, \& Silver, 1987). Schoolteachers and administrators often seek consultative services from individuals who have specialized training in behavior. Traditionally, these consultants provide indirect services to assess the problem behavior, suggest an intervention, and evaluate the intervention effectiveness (Witt, Gresham, \& Noell, 1996). That is, the consultant may never observe or meet the child who is the target of the consultation services. However, new directions in behavior consultation have been moving toward more direct models of service delivery, such that the consultant has in-vivo interactions with both the teacher and child within the target setting regarding the behavior of concern (e.g., Erchul \& Martens, 1997; Noell, Witt, Gilbertson, Ranier, \& Freeland, 1997; Witt, 1997; Watson \& Robinson, 1996).

Recent advances in school behavior consultation suggest that reliance on parent-training research may be beneficial in the development of innovative direct models of behavior consultation (e.g., Watson \& Robinson, 1996). Numerous studies in the parent training literature have examined methodologies for changing parent behavior (e.g., role-play, coaching) or techniques for modifying child behavior (e.g., labeled praise, giving effective instructions). Furthermore, in both parent training and school consultation, an individual seeks consultative services in order to effect behavior change in a target child. Although the use of a third party to 
teach an individual ways to improve a target person's behavior has been used in other settings, (e.g., Ivancic, Reid, Iwata, Faw, \& Page, 1981), it has been researched most extensively in the behavioral parent training literature (e.g., Eyberg \& Matarazzo, 1980; Forehand \& McMahon, 1981; Hembree-Kigin \& McNeil; Moreland, Schwebel, Beck, \& Wells, 1982). Finally, effective parent training techniques developed to improve the behavior of young children with disruptive behavior have been well established (e.g., Forehand \& McMahon, 1981; Hembree-Kigin \& McNeil, 1995; Webster-Stratton, 1981). Although empirical support exists for many parenttraining programs, Parent Child Interaction Therapy (PCIT; Hembree-Kigin \& McNeil, 1995), a program that was developed specifically for young children with disruptive behavior problems, will serve in this study as the basis for a new model of behavior consultation in preschool classrooms.

To further explain this new model of preschool consultation, a typical or traditional model of consultation regarding behavior management will be described first. Next, the similarities between parent training and teacher training will be delineated, providing further rationale for applying a parent training program to a school context. Following, a general description of PCIT will be provided, highlighting the potential benefits of PCIT for preschool classrooms, particularly Head Start classrooms. Finally, a methodology will be proposed to evaluate the effectiveness of adapting PCIT for the purpose of training Head Start teachers to manage disruptive behaviors.

\section{$\underline{\text { School Consultation }}$}

School consultation is a broad term that can encompass a range of services that are designed to bring about change in many areas related to the functioning of a school, including administrative issues, academic programming, or systemic problem solving. Also, school 
consultation may focus on a single teacher's behavior management strategies (Sugai \& Tindal, 1993). Of the variety of services that are encompassed under the umbrella term "school consultation," the type that focuses on improving child behavior, referred to as behavior consultation, is most common (Gutkin \& Curtis, 1990; Kratochwill \& Bergan, 1990).

The goal of behavior consultation is to effect behavior change in both the target child and the teacher in the most time-efficient manner (Kratochwill \& Bergan, 1990). To accomplish this goal, behavior consultation follows a four-stage sequence: (a) problem identification, (b) problem analysis, (c) plan implementation, and (d) plan evaluation (Bergan, 1977; Kratochwill \& Bergan). Often, this approach is indirect, and relies on teacher report of child behavior for program evaluation. Also, although the consultant could serve as a supervisor, typically the teacher bears the ultimate responsibility for the program implementation.

The most common approach for training teachers to use new interventions to target children's disruptive behavior, as typically is done in traditional behavior consultation, is didactic instruction (e.g., Sugai \& Tindal, 1993). Although reasons for using a didactic approach are numerous (e.g., time-efficiency, easy dissemination of information), the effectiveness of this approach for training new skills has been called into question (Witt, 1997). Therefore, recent suggestions for changing behavioral consultation have steered away from the indirect, didactic methods of implementation to more direct intervention procedures, such as functional analyses, coaching, using behavioral indices of treatment acceptability, and the observational monitoring of baseline, progress, and plan implementation (e.g., Noell, Witt, Gilbertson, Ranier, \& Freeland, 1997; Shapiro, DuPaul, Bradley, \& Bailey, 1996; Watson \& Robinson, 1996; Witt, 1997; Witt, Gresham, \& Noell, 1996). These direct consultation methods are consistent with behavior 
analytic interventions that typically have been implemented in special education classrooms (e.g., Vollmer, Marcus, \& LeBlanc, 1993).

Behavior analytic approaches deviate from traditional behavioral consultation procedures in a few broad ways. First, the behavioral assessment procedures and development of an intervention are more thorough than those employed in indirect consultation models (Witt, Gresham, \& Noell, 1996). Second, evaluation of the intervention is based on objective observations of behavior rather than teacher report. Third, the consultant explicitly teaches, often in-vivo, precise strategies for working with a child with extremely disruptive behaviors. Therefore, behavior analytic approaches are more direct than traditional behavior consultation.

One specific model of this type of consultation is Direct Behavioral Consultation (Watson \& Robinson, 1996). In addition to stressing the importance of functional analysis in behavior assessment and intervention development, Watson and Robinson emphasize the integration of parent-training research as a springboard for the development of more efficacious behavior consultation. Direct Behavior Consultation primarily focuses on the use of direct coaching as a method of training new skills to teachers. Although training strategies are addressed in the Direct Behavior Consultation model, it does not extend itself to incorporating other components of parent training, such as the specific skills taught, into the consultation model. Thus, a logical extension of Direct Behavior Consultation is to adapt a parent training model to a classroom setting, including both the parent training strategies and behavior management skills. A description of a parent training model that can be adapted for classroom behavior intervention follows. 


\section{Parent-Child Interaction Therapy}

Parent-Child Interaction Therapy (PCIT; Eyberg, 1988; Eyberg, Boggs, \& Algina, 1995; Hembree-Kigin \& McNeil, 1995) is an empirically validated parent-training program for parents of preschool-age children with extremely disruptive behavior. This 2-stage parent-training program, based on the Hanf (1969) model of treatment, is unique because it relies heavily on coaching. The stages of PCIT, the use of direct coaching, and the adaptation of this parenttraining program to a classroom setting will be presented.

\section{Stages of Parent-Child Interaction Therapy}

The first stage of PCIT, the child-directed interaction, focuses on positive interaction skills that parents can use to enhance their relationship with their child (Eyberg, 1988; HembreeKigin \& McNeil, 1995). Parents are taught four specific, positive skills (e.g., Roberts, 1979; O’Leary, O’Leary, \& Becker, 1967) to use while interacting with a young child. These skills are description, reflection, imitation, and praise. Reflections and descriptions are verbal statements that either describe what the child is doing or reflect back what the child is saying, respectively. In addition to modeling appropriate speech, descriptions convey that a parent is interested in what their child is doing. Reflections are useful in demonstrating to the child that the parent has paid attention to what the child said, and also are useful for increasing verbal communication. Imitation is taught so that parents follow their child's play. By imitating, parents can model how to play with others while enjoying being involved with their children. Finally, praise is any positive statement that a parent says about the child. It has been suggested that labeled praise, or praise that clearly identifies the desirable behavior, is more effective than unlabeled praise for changing behavior (Hembree-Kigin \& McNeil, 1995). In addition to training parents to use these 
skills at high rates, they are instructed to avoid asking questions, giving commands, or using criticism during this stage.

In addition to training parents to use the four positive skills at high rates, they are instructed to avoid asking questions, giving commands, or using criticism during this stage for a few reasons. When parents ask questions, they tend to lead the play and conversation. Parents are taught to avoid commands because they take the lead away from the child, but also because child obedience and the effective use of commands are taught in the second stage of PCIT. Finally, parents are taught to avoid criticizing their children because it causes unpleasant interactions and (Hembree-Kigin \& McNeil, 1995). Additionally, criticism often is not effective for decreasing disruptive behavior with children who have behavior problems because it involves negative attention, which often serves as a reinforcer.

Two related skills that also are taught during the child-directed interaction stage are strategic attention and selective ignoring. Parents are taught to "catch" their child "being good," and to use labeled praise or another form of attention for these appropriate behaviors. Selective ignoring, on the other hand, is a skill in which parents are directed to ignore behavior that is annoying or disruptive. To do so, parents turn their backs completely, conducting a type of timeout procedure, until the child again engages in appropriate behavior. Because these skills are effective only if the behavior is maintained by parental attention, it is important to delineate behaviors that might be maintained by other consequences. For example, it is unlikely that taking an extra piece of candy would be maintained by attention. Thus, strategic attention and selective ignoring are effective strategies for managing attention-maintained behaviors.

The second stage of PCIT, the parent-directed interaction, sometimes is referred to as the compliance or discipline component. During this stage, parents are taught how to give effective 
commands, use a two-choices statement, and implement a timeout procedure for noncompliance. Commands are statements that directly specify the response expected from the child. A twochoices statement specifies two response options from which the child must choose (i.e., either compliance or timeout). The rationale for teaching parents to give effective commands and use two-choices statements is to provide opportunities for compliance without needing to implement a timeout consequence. However, inappropriate behaviors, such as noncompliance, are followed by an aversive consequence (i.e., timeout) which is taught in this stage of PCIT. One unique feature of the parent-directed interaction component is that parents rehearse the steps of timeout with their child prior to its actual use. By rehearsing in advance, the sequence of timeout events and the expected behavior are explained to the child at a neutral time, rather than in the midst of a negative interaction.

\section{Direct Coaching}

The use of a direct coaching model, as done in PCIT, is not a new idea for parent training; however, it is not used by many parent training programs. Direct coaching models are characterized by the therapist giving in-vivo direct instructions to parents while the parents are interacting with their child. In his review of behavioral parent training research, O'Dell (1974) mentioned a few parent-training programs in which the therapist used some method of signaling the parent as to when to use particular skills. For example, strategies such as visual cues (Wahler, Winkel, Peterson, \& Morrison, 1971), hand signals (Hawkins, Peterson, Schweid, \& Bijou, 1966; O’Leary, O’Leary, \& Becker 1967), and walkie talkies (Bernal, Williams, Miller, \& Reagor 1972) were used to indicate to parents when to use one of the specified skills. Today, some clinics are equipped with a wireless microphone that transmits to an earpiece that the parent wears in the clinic, known as a bug-in-ear (available from Mind Works). Using this, the therapist 
can observe the parent and child from behind a one-way mirror and communicate directly with the parent during the parent-child interactions. In PCIT, the wireless microphone and earpiece are used, thus enabling the therapist to give direct and immediate feedback following every parent verbalization.

Hembree-Kigin and McNeil (1995) argue that direct coaching has several advantages over the more traditional methods of training (e.g., didactic instruction, modeling, rehearsal). First, direct coaching allows the therapist to correct errors quickly so parents do not repeatedly practice incorrect techniques. Also, this method allows the therapist to adapt the skills being taught to manage unique behavior problems as they arise. Furthermore, direct observation and coaching decreases the need to rely on parental report that may not be completely accurate. By providing immediate, positive feedback, the therapist can prompt, shape, and reinforce the parents' appropriate skill usage. Finally, as parents become more adept at using the newly trained skills, the therapist can fade out prompts and directives.

Adapting Parent-Child Interaction Therapy to the Classroom

Because PCIT has been shown to be effective for managing the disruptive behavior of children between the ages of 2 and 7 in a clinical setting, it follows that adaptation to the classroom may be beneficial. The skills used in PCIT that are likely to be useful in a classroom can be divided into two broad categories. Analogous to the child directed and parent directed components of PCIT, the two categories of skills that make up the content of classroom modification are techniques for (a) selective attention, and (b) compliance training. Several examples demonstrating the use of these skills in the classroom will be presented. In addition, adaptations of these skills will be suggested, as modifications must be made when applying skills originally designed to be used in homes to classroom situations. 


\section{$\underline{\text { Selective Attention }}$}

The use of teacher attention to strategically reward appropriate child behavior is referred to as selective attention. Attention often serves as a reinforcer for a variety of child behaviors. Thus, selective attention to appropriate behaviors, and, in turn, ignoring inappropriate behaviors, will result in behavioral improvements for attention-maintained behaviors. In PCIT, description, reflection, and labeled praise are used to increase appropriate behaviors, while tactical ignoring is used to decrease inappropriate behaviors. In this next section, each of these selective attention skills will be described and examples will illustrate how to use the skills in preschool classrooms.

Descriptions and reflections. Descriptions and reflections are two types of statements that can be used to selectively attend to a child's behavior (Hembree-Kigin \& McNeil, 1995). These skills provide a way for teachers to express interest in a child's work or play, while not drawing them away from the activity in which they are engaged. Also, these are skills that can be used frequently throughout the day with all of the children in the class. The teacher can be taught to walk through the classroom, quickly commenting on many of the children's activities during free play or structured activities. For example, the teacher's running commentary might sound like, "Jeremy is painting in red. Oh, and you are drawing in blue. And Tricia, you're reading a book quietly on the carpet...yes, Sam, that is a tall tower!" Certainly, there are times during the day that lend themselves more readily to this type of interaction. As a general principle, however, descriptions and reflections are beneficial skills because teachers can use them often to selectively attend to appropriate behavior.

Labeled praise. Research has demonstrated that contingent teacher praise, otherwise referred to as descriptive or labeled praise, is an effective technique for increasing appropriate behaviors and decreasing oppositional behaviors in elementary classrooms (Pfiffner \& Barkley, 
1990). Descriptive, or labeled, praises are positive statements, such as "Thanks for sharing," that explicitly identify the approved behavior. This type of praise may be used in several ways to encourage, or discourage, appropriate and inappropriate behaviors, respectively.

First, labeled praise is useful in the classroom for indirectly teaching desired behaviors without resorting to the use of a direct command. That is, a teacher can praise the behavior of a child who is engaging in the appropriate behavior, thus teaching other children the appropriate behavior. For example, if during a circle time, a child is rolling around on the floor, the consultant could coach the teacher to say "I like the way Alex is sitting up, and Tanya is doing a great job sitting up too." When the child who was rolling around sits up, the teacher can immediately praise the child's appropriate behavior (e.g., "Thank you for sitting up so nicely"). This way, the teacher teaches the appropriate behavior without using one of the more confrontive strategies, such as those that will be discussed in the compliance section (e.g., direct command).

Second, labeled praise also may be useful for increasing the occurrence of desirable behaviors that already are occurring, but at low rates. For example, if a teacher "catches" a child engaging in an appropriate behavior, but one that this child infrequently exhibits, using labeled praise to attend to this behavior is likely to increase its occurrence in the future. One behavior that often is encouraged in a preschool classroom, but may occur at low rates, is sharing. Thus, this is one situation in which a teacher may "catch" the child "being good" (i.e., sharing the Legos), and the teacher could say "I like it when you share with your friends!" Using labeled praise this way will help to increase the occurrence of low-rate, appropriate behaviors.

A third way that labeled praise can impact children's behavior in a classroom is by decreasing the rates of annoying or disruptive behavior. This is done by using labeled praise to increase the opposite, or incompatible, behavior. For example, if a child is crumbling pieces of 
playdough into her hair, but begins to roll out a piece on the table, the consultant could guide the teacher to say "You're a good girl for keeping the playdough on the table." Because behaviors that are praised are likely to occur more often in the future, and keeping playdough on the table is incompatible with sprinkling it on one's head, the inappropriate behavior is likely to reciprocally decrease as the appropriate behavior increases. Thus, praising an incompatible behavior is another way to use labeled praise to decrease inappropriate behavior.

\section{$\underline{\text { Tactical Ignoring }}$}

In conjunction with selective attention, it is important that the teacher ignores inappropriate behaviors that are annoying or disruptive, particularly if the function of those behaviors is to get attention. For example, if a child is making snorting noises while the teacher is reading a story to the class, the teacher can continue reading the story and ignore the child's noises. At a moment when the child is not snorting, the teacher can say, 'Thanks for listening quietly,' and then go on with the book. However, three potential pitfalls of ignoring in the classroom must be addressed. First, unlike the parent's attention in PCIT, the teacher's attention typically is not focused completely on one child. Thus, there is not a clear indication to the child that the teacher is selectively ignoring the annoying behavior. Second, other children in the class may laugh or join in snorting with the child, and therefore may reinforce the inappropriate behavior with social attention. Third, other children may not know that the teacher is ignoring the misbehavior, and may think that the child engaging in the inappropriate behavior is getting away with it. This could result in other children escalating if they believe that a teacher is not consequating inappropriate behavior. The use of an ignoring signal is one way to inform all the children in the class, including the target child, that a specific behavior is not acceptable. 
Ignoring Signal. An ignoring signal is any indication that a particular child will not be responded to while she or he is engaging in an inappropriate behavior. In PCIT, parents turn their backs when a child engages in inappropriate behavior; this serves as a kind of "signal" to the child. For the classroom, however, a more direct signal is necessary to address some of the pitfalls mentioned previously. The signal must be salient not only to the target child, but also to other children in the class. Other studies have found that an indicator, such as a timeout ribbon worn around a child's neck (Foxx \& Shapiro, 1978), can be used to effectively signal to the target child as well as other children in the class that the behavior is inappropriate and will not be rewarded with social attention. To be effective, it is important that the teacher rehearse using the signal in advance with the children to teach them the appropriate, expected responses. For example the teacher could use a "closed-mouth" hand signal that involves folding the four fingers of his or her hand against the thumb, and maintaining that signal in the direction of the child. This way, the child would be given a clear indication that the teacher is aware of the behavior and is not going to give other attention, such as talking to or looking at the child, while the child is engaging in the inappropriate behavior. Also, the signal can be an indication to other children that they are not allowed to look at, laugh with, or talk to the target child, and these behaviors can be praised. When the child stops the inappropriate behavior, the teacher can remove the signal and praise the child for an incompatible, appropriate behavior. Although variations of indicating ignoring, such as parents turning their backs or the use of a visual marker (e.g., the timeout ribbon), have documented efficacy, the ignoring procedure suggested here is one that does not yet have empirical support. 


\section{Compliance Training}

For a teacher to successfully manage the behavior of many children, it is critical that the children comply with directions. One of the most frequent behavior problems reported by parents is noncompliance (see Forehand \& McMahon, 1981), and it is likely that this concern carries over to the classroom. In a classroom, cooperation with teacher instructions is one of the key aspects of a preschool classroom that runs smoothly. Just as conflict arises between children and parents due to noncompliance (Forehand \& McMahon), conflict between a teacher and child can arise when a child is noncompliant with teacher requests. Based on techniques used in PCIT, there are several skills that teachers can use that might increase child compliance. Specifically, the use of appropriate commands, two-choice statements, compliance exercises, and timeout may impact compliance.

Giving good commands. In a preschool classroom, good commands might be used for directing children to move to a new activity, such as music or snack. Commands include any statements that specify the behavior that is expected of the child. It is particularly important that children are compliant with commands during activities outside the classroom setting, such as on field trips. The following five guidelines are important for generating commands that will increase the likelihood of child compliance.

First, it is important that the commands are direct rather than indirect. A direct command explicitly states the expected response. In contrast, indirect commands may be suggestions, such as "Let's put the markers away now," or questions such as "Would you please put the markers away?" These indirect commands allow for children to respond that they do not want to clean up the markers. However, a direct command (e.g., "Please put the markers away now.") does not suggest that compliance is optional. 
Second, as demonstrated in the previous example, it is important for teachers to be polite when stating a command. First, this may help to foster mutual respect between the teacher and students, as well as between students, in the classroom. Also, the word "please" can serve as a discriminative stimulus for the child's listening to and complying with a direct command. Further, by being polite, the teacher serves as a model of appropriate social skills for the children.

The third guideline for giving good commands is to state them positively. That is, children should be told what they are expected to do rather than what not to do. Thus, it is important for teachers to (a) label the behavior that they want to stop, (b) think of the opposite behavior or an incompatible response, and (c) positively state a command for the child to engage in the incompatible behavior. For example, if a child is painting on her hand, the consultant could coach the teacher to say "Elena, please paint on your paper."

Fourth, the commands must be specific. A child's interpretation of a vague statement such as, "be good," might be quite different from the behavior changes the teacher expects. One way to state this more explicitly is to say, "Please keep your hands in your lap," or "Please use your inside voice."

Fifth, it is important that teachers use a neutral tone of voice when stating commands. Often consultants are called upon to work with a teacher who has resorted to yelling as a means of obtaining compliance. Unfortunately, when teachers yell, children learn that they do not need to comply until the teacher begins to use a louder tone of voice. When teachers state commands using a neutral tone of voice and give consistent consequences for noncompliance, children learn to comply with these commands. 
Using a two-choices statements. The two-choices statement that precedes timeout in PCIT also can be used in the classroom. This type of statement provides two response options from which the child must choose. Two-choices statements should follow a direct command issued by the teacher. A two-choices statement begins with the statement, "You have two choices (with a visual cue, holding up 2 fingers)," and is followed by an either-or statement (e.g., "you can either keep your snack in your mouth or you can go to timeout"). Often, two-choices statements serve to decrease the need for more confrontive strategies, such as timeout, because both the desired response as well as the consequence for noncompliance are clearly stated. Therefore, the child is given a second chance to comply with the initial command before the timeout consequence is implemented.

Timeout in the classroom. Timeout can be used in the preschool classroom, or in another room with a supervisory adult other than the teacher. Because timeout is more confrontive than many of the strategies discussed previously, it should be used as a last resort. For example, it is important that basic rules, such as "no hurting," are enforced to maintain safety for all children in the class; thus, timeout could be a consequence established for violating rules designated as "safety rules." Also, time-out can be used for as a consequence for noncompliance with a twochoices statement or other circumstances of repeated noncompliance. Certain steps might help lead to a more effective timeout procedure. One of the most important steps is for the teacher to rehearse timeout in advance with the children. Rehearsal in advance has three significant benefits. First, the teacher gains experience implementing the steps of timeout in a situation that has not escalated and is essentially pressure-free. Second, the children learn both the timeout procedure and the behavior that is expected of them during a timeout. Third, children will be less likely to test the limits when placed in a real timeout because the consequences already have 
been rehearsed. In teaching timeout, the consultant could fulfill several roles, such as directly teaching the children the rules of timeout or coaching the teacher word-for-word through teaching or implementing a timeout, as is done in PCIT. Timeout can be an effective consequence in the classroom not only for increasing compliance, but also for violations of preestablished classroom safety rules.

Coaching

Similar to PCIT, coaching a teacher with a bug-in-ear device is a desirable method of training for several reasons. First and foremost, this method of training has empirical support demonstrating the greater effectiveness of this manner of feedback over other methods because the consultant is able to provide immediate, direct feedback to the teacher about the skills being used. For example, Martin and Pear (1996) examined the value of immediate versus delayed feedback on task performance, concluding that optimal results (e.g., greatest behavior change) are obtained in immediate feedback conditions. A second advantage of bug-in-ear coaching is that the consultant can give the teacher step-by-step directions on what to say or do at that immediate instant. For example, if a child who has been spinning in circles on the floor sits with another child to work on a puzzle, the consultant could direct the teacher to give the child immediate attention (e.g., "I like the way you're helping with the puzzle."). Thus, the consultant can direct the teacher's attention to "catch" the child "being good." Also, the consultant can help the teacher generate an appropriate response, helping to take the pressure off the teacher in a situation that could benefit from a quick response. Third, with a bug-in-ear device, the consultant can coach from a distance. In this way, the consultant still can provide immediate feedback to the teacher, but with minimal class disruption. 
Process of coaching. Hembree-Kigin and McNeil (1995) have referred to the process of coaching as an art: that is, coaching is a skill that develops as the therapist gains professional experience. The following suggestions are basic guidelines for coaching in a classroom that have been adapted from PCIT (Hembree-Kigin \& McNeil).

It is important that during coaching, the consultant remains focused on the positive aspects of what the teacher already is doing. The consultant is, in effect, modeling for the teacher how to focus on positive child behaviors. One way to help the consultant remember to do this is to avoid saying the following five words: "no," "don't," "stop," "not," "quit." These words focus on decreasing an inappropriate or unwanted behavior, hence emphasizing the negative aspects of a teacher's behavior. For example, if the consultant says, "Don't correct her each time she blurts out an answer," the focus would be on the teacher behaviors that should decrease. However, if instead the consultant says, "You did a great job waiting for someone to raise their hand before paying attention to any answers," then the focus is on what the teacher did well. By remembering to focus on the positives, the consultant may be more likely to receive greater cooperation from the teacher.

Giving frequent, immediate feedback is another strategy that is likely to make coaching in the preschool classroom more effective. As stated earlier, research has demonstrated that immediate feedback is more effective than delayed feedback for behavioral change. Also, the consultant can shape the teacher's skills if feedback follows most verbalizations regarding child behavior rather than if feedback follows every fifth or sixth teacher-child interaction. Another reason for giving frequent and immediate feedback is that a smooth rhythm is likely to develop if the teacher is able to predict that the consultant is going to provide feedback following almost every verbalization or use of a skill. Considerable attention must be paid to the manner in which 
information is presented to the teacher during the coaching period. This specific feedback can be given in the form of (a) labeled praise (e.g., "Excellent job with that timeout!"), (b) directives (e.g., " Please say "Ben, when you put your coat on, then you can come outside."), (c) observations (e.g., "I noticed that Sara really sat up quickly when you used that ignoring signal."), or (d) gentle corrections that avoid using no, don't, stop, not and quit (e.g., "That may have been a good time to use a direct command.").

Coaching that is specific rather than vague likely is more beneficial. Specific feedback, such as "You were nice and calm when you said that two-choices statement," probably will increase the good skills that the teacher uses because the desirable skill was clearly identified and rewarded. In addition to being specific, coaching statements must be brief. Feedback must be concise because teachers have little time to listen to lengthy feedback while maintaining interactions with the children in the class.

It is important to point out to the teacher the changes that occur in child behavior following the use of the behavioral skills. For example, the consultant may coach the teacher to tactically ignore a child who is parading around the room wearing a dress-up skirt on her head during clean up. In turn, the teacher should be directed to selectively attend to children who are cleaning up appropriately. When the child wearing the skirt on her head begins to straighten the clothes in the dress-up corner and puts the skirt away, the consultant can point out to the teacher that the tactical ignoring and selective attention were powerful skills for improving that child's behavior. Using this strategy during coaching may help accomplish two goals. First, teachers will begin to notice changes in children's behavior following their consistent use of behavioral skills. Second, these positive changes in child behavior are likely to reinforce the teacher's use of the 
behavior management skills. Hence, when the consultant points out changes in child behavior, maintenance of the teacher's newly applied skills can be fostered.

A final suggestion for the process of coaching is that the consultant can begin to fade out the directiveness and intensity of coaching as the teacher begins to acquire more skills. Initially, the consultant may need to give the teacher exact statements to say during teacher-child interactions. As the teacher becomes more skilled, however, the teacher will be able to generate adequate comments without relying on the consultant to provide the exact words. At this point, the consultant can move from a guidance role to more of a feedback role. As the teacher's skills continue to improve, the consultant can begin to fade out the intensity of coaching, thereby facilitating the transition of the consultant out of the classroom and establishing the teacher as the sole responsible individual for classroom behavior management.

Purpose of Study

This study evaluated the utility of adapting PCIT and the coaching model to train effective behavior management skills to classroom teachers. First, the overall effectiveness of using PCIT to train behavior management skills was assessed. Second, the importance of using direct coaching of skills in addition to didactic training was analyzed. The impact of the modified PCIT on both child and teacher behavior was evaluated. A multiple baseline design across classrooms was used. The PCIT skills initially were introduced in a didactic phase in each classroom. Second, PCIT skills were taught by in-vivo coaching in two classrooms, and re-taught in didactic format in the third classroom. In addition to the evaluation of PCIT as a new method of behavior consultation for preschool-age children, this design allowed for the assessment of the additive effects of coaching over didactic methods of training. 
Method

\section{$\underline{\text { Setting and Participants }}$}

$\underline{\text { Setting }}$

Three local Head Start classrooms were used for this study. Each classroom was located at a different school. There were 17 children in two classrooms and 16 children in one classroom. Head Start is a preschool education program that provides education, health care, nutrition, and social services to children and families whose annual income is below the poverty line. Although Head Start primarily provides services to impoverished children, they are mandated to allocate $10 \%$ of their enrollment to children with special needs, including physical, cognitive, speech and language, and behavioral impairments. All phases were conducted in the children's regular classroom with their regular teacher and teacher's aide.

\section{$\underline{\text { Participant Selection }}$}

Teacher participants. Both the teacher and the teacher's aide (i.e., the teaching team) from three classrooms participated in this study. Therefore, a total of six teachers - three teachers and three teachers' aides - participated in this study. All six teachers were white females who had varying levels of experience teaching in Head Start. The teachers received $\$ 100$ for their participation. Administrators from Head Start informed the teaching teams generally about the research study. The experimenter described the study in more detail to those teachers who expressed interest, and teaching teams signed consent forms. Teaching teams who volunteered were included in the study on a first come/first serve basis. Days that the primary teacher was absent were omitted from the study because substitute teachers did not have prior knowledge of the study, nor were they instructed on the use of any behavior management strategies. 
Child participants. Two children from each of the three classrooms were identified to participate in this study. Therefore, a total of six students participated in this study. All participants were 4-years old at the onset of the study. Of the participants, four were white males and two were white females. Five participants were typically developed and one (i.e., Jill) was receiving services for speech and language delays. None of the particiapnts were reported to be taking medication for behavior problems. The procedure for selecting participants was an adaptation of the procedure used in previous studies (e.g., Bahl, McNeil, Cleavenger, Blanc, \& Bennett, in press; Funderburk, 1989). The measures used to select participants are described in detail in the "Measures" section of this document.

First, informed consent was obtained from the parents of the children in each of the three classrooms. Next, each classroom teaching team completed the behavior rating scale for all the children who received parental consent. Using the disruptive category of the behavior rating scale, four children from each class who had the highest ratings on the disruptive behavior subscale were selected by the investigator. The teacher and the teacher aide each completed the Sutter-Eyberg Student Behavior Inventory (SESBI; Sutter \& Eyberg, 1984) for these four children. Based on the SESBI scores, two children with the highest SESBI scores were selected for observation in each classroom. Overall, two children with disruptive behavior were selected from each of the three classrooms for observation purposes (i.e., a total of six child participants).

\section{Measures}

\section{$\underline{\text { Selection Measures }}$}

Two teacher report measures were used for the purpose of selecting child participants. First, a behavior rating scale was completed. Four children in each class were identified for further screening based on their scores on this measure. For selection purposes, the teachers 
completed the Sutter-Eyberg Student Behavior Inventory (SESBI; Sutter \& Eyberg, 1984) for the four students in their classroom.

$\underline{\text { Behavior Rating Scale }}$

As part of the child participant selection procedure, teaching teams completed this 5point Likert scale (Bahl, et al., in press; Funderburk, 1989). A rating of 1 represented the fewest behavior problems in relation to the rest of the class. The children with the most behavior problems in relation to the rest of the class were assigned ratings of 5. Children assigned ratings of 3 represented those with average behavior. In addition to rating disruptive behavior, the teachers were asked to rate how outgoing and cooperative each child is, to de-emphasize the focus on disruptive behavior (see Appendix C). The behavior rating scale was used only for initial screening of possible participants. Actual selection of the participants was done using the Sutter-Eyberg Student Behavior Inventory (Sutter \& Eyberg, 1984).

\section{Sutter-Eyberg Student Behavior Inventory}

The Sutter-Eyberg Student Behavior Inventory (SESBI; Sutter \& Eyberg, 1984) is a 36item teacher report measure designed to assess disruptive behavior problems in children ages 2 to 16 (see Appendix D). An intensity score of 151 and a problem score of 19 is considered the cutoff for indicating clinically significant behavior problems at school (Eyberg \& Pincus, 1999).The SESBI has been demonstrated to have adequate concurrent validity, internal consistency coefficient (i.e., Cronbach's alpha $=.98$ ), test-retest correlations (i.e., .90), and discriminative ability between nonreferred samples and school behavior problem samples of children aged 3- to 5-years old (Funderburk \& Eyberg, 1989). Furthermore, in several studies, the SESBI has demonstrated sensitivity to changes in child behavior over the course of PCIT (e.g., McNeil, Eyberg, Eisenstadt, Newcomb, \& Funderburk, 1991). 


\section{$\underline{\text { Outcome Measures }}$}

The measures are organized into three broad categories: (a) behavior observation measures - teacher and child; (b) teacher-report measures; and (c) treatment integrity checklists.

\section{Behavior Observation Measures}

Child behavior. The child participants' behavior was coded as either Appropriate or Oppositional using a behavior observation system that was an adaptation of a classroom coding system used in previous studies (e.g., McNeil et al., 1991). In general, Appropriate Behavior was defined as the absence of oppositional behavior. For the purposes of this study, Oppositional Behavior included being noncompliant, off-task, or disruptive to others. Noncompliance was defined as when the target child makes no movement toward obeying a direct or indirect teacher command during a 5-second period following the command. A child was considered to be offtask if he or she failed to attend to or work on the assigned task, broke classroom rules (e.g., out of seat, talking out, disturbing others, etc.), lay head on desk passively when there was a task to complete, or daydreamed. Interacting with the teacher or classmates about academic matters or listening to teacher instructions and directions were considered to be on-task behaviors. If a coder was unsure whether behavior was appropriate or oppositional, a code of Appropriate Behavior was given. For more detailed definitions, see Appendix A.

Teacher behavior. Portions of the Dyadic Parent-Child Interaction Coding System (DPICS; Eyberg \& Robinson, 1983) were used to code teacher behaviors (see Appendix B; for more details see Eyberg \& Robinson). The DPICS is a 24-category observational coding system that was designed to assess parent-child interactions during the course of PCIT (Eyberg \& Robinson). Adequate interrater reliability for collapsed categories of child and parent behavior has been obtained (Robinson \& Eyberg, 1981). The DPICS has been demonstrated to be 
sensitive to treatment effects in several studies (e.g., Eyberg \& Robinson, 1982; McNeil et al., 1991; Robinson \& Eyberg, 1981; Webster-Stratton, Hollinsworth, Kolpacoff, 1989). For this study, the following categories were used: (a) descriptive statement; (b) reflective statement; (c) labeled praise; (d) unlabeled praise; (e) criticism; (e) direct command; (f) indirect command; (g) question. The DPICS definitions were to be adhered to for these categories. Additionally, a category for incomprehensible statements was added to account for unclear utterances. The descriptive and reflective statement categories were combined and coded as one category (i.e., descriptive/reflective statement), and the direct and indirect commands will be represented as a percentage of direct commands. The following formula was used to calculate the direct command percentage:

$\frac{\text { \# of direct commands }}{\text { \# of indirect }+ \text { direct commands }}$.

\section{$\underline{\text { Teacher-Report Measures }}$}

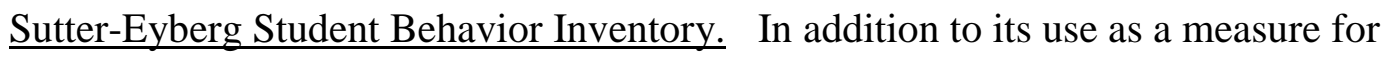
selecting child participants, the SESBI (Sutter \& Eyberg, 1984) also was used as an outcome measure. For outcome evaluation purposes, the teachers completed the SESBI on at the termination of each condition (i.e., baseline, didactic, coaching).

Teacher satisfaction questionnaire. The teacher satisfaction questionnaire (see Appendix E) is a 10-item measure that has been adapted from the Therapy Attitude Inventory (TAI; Eyberg, 1974). The TAI is a 10-item questionnaire that assesses parental satisfaction with PCIT. Nine of the 10 items on the teacher satisfaction questionnaire are nearly identical to the questions asked on the TAI, with the only changes being changes regarding individual children versus 
children in the classroom. One of the questions from the TAI was not applicable to the classroom setting (i.e., "To what degree has the treatment program helped with other general personal or family problems not directly related to your child in the program?"). Thus, the question, "How likely are you to recommend this behavior management program to another teacher?" which was used on a satisfaction measure in a previous classroom study (Bahl, et al., in press) was added. The scores on the teacher satisfaction questionnaire range from 10 to 50, with 50 indicating the highest level of satisfaction.

\section{$\underline{\text { Treatment Integrity Checklists }}$}

To evaluate the integrity of the treatment provided, two checklists were developed: one for the didactic sessions and one for the coaching sessions. The didactic integrity checklist was developed by identifying the PCIT skills to be taught and requiring that a definition and example be provided for each. The coaching suggestions provided by Hembree-Kigin \& McNeil (1995) were used as general guidelines for developing the coaching integrity checklist.

\section{$\underline{\text { Reliability and Response Measurement }}$}

\section{$\underline{\text { Training Coders }}$}

Training for both the child and teacher behaviors involved review of the coding definitions, didactic instruction, videotape review of child-adult interactions in classroom and clinical settings, and in-vivo training. Upon acquiring $80 \%$ interobserver agreement on the videotaped observations, in-vivo training was begun using pilot children. A minimum criterion of .80 Kappa coefficient on three consecutive classroom observation sessions was established for the child behavior coding. For the teacher behavior coding, percent agreement was calculated by dividing agreements by the number of agreements plus disagreements. Upon acquiring $80 \%$ interrater agreement on the videotape coding, in-vivo observation training began. Prior to 
beginning data collection, observers met a minimum criterion of $80 \%$ interrater agreement on three consecutive classroom observation sessions.

Child behavior. Five advanced undergraduate students were trained by the experimenter to serve as observers. One or two observers functioned as primary coders in each classroom, depending on their scheduling availability (i.e., two classrooms had two primary coders who observed on different days from each other and one classroom had one primary coder). The primary investigator and some of the primary coders served as the reliability coders. The observers were unaware of the expected outcomes of the study. Additionally, observers were unaware of the experimental condition underway. The observers were trained to code data using the modified classroom coding system.

Teacher behavior. Initially, coders were trained to code teacher behavior using the modified DPICS. The coders were provided with the DPICS code definitions and these were discussed in detail. Videotapes of parent-child interactions were used until an $80 \%$ interobserver agreement was obtained, at which time videotapes of teachers in classroom settings were introduced. Again, an $80 \%$ interobserver agreement criterion was used, following which live classroom coding was initiated. If agreement had fallen below $80 \%$ on three consecutive sessions in the classroom, data collection would have ceased and training would have been reinitiated. However, due to the acoustics in the classroom, we were unable to attain a satisfactory agreement percentage. Therefore, audiotapes were used to record teacher verbalizations and a new coder who had not spent time in the classroom was trained to code the audiotapes.

The primary coder of the audiotaped teacher verbalizations was trained on the DPICS coding system prior to participation in the coding for this study. Thus, the DPICS codes were 
reviewed and audiotaped teacher interactions were used for further training. A minimum criterion of $80 \%$ agreement on three consecutive audiotaped classroom sessions was established prior to coding. Percent agreement was calculated by collapsing across the DPICS categories (i.e., descriptive/reflective statement, labeled praise, criticism, direct command, indirect command) and dividing the number of agreements by the number of agreements plus disagreements. Adequate percentages of interobserver agreement (i.e., $91 \%$ or better on three consecutive sessions) were obtained prior to beginning coding.

\section{$\underline{\text { Treatment Integrity }}$}

The coders reviewed audiotapes of the didactic sessions for overall content according to the designated skills for that session and coded on the didactic integrity checklist (see Appendix F). The obtained treatment integrity for the didactic sessions across classrooms was $100 \%$.

Coaching behavior was recorded on the coaching integrity checklist (see Appendix G). Coders completed treatment integrity checklists on $25 \%$ of the coaching sessions to assess adherence to pre-determined treatment criteria. However, this integrity check was conducted across randomly selected, 30-minute segments of coaching sessions rather than on just one of the individual coaching sessions. The obtained treatment integrity for the coaching sessions across classrooms was $96 \%$.

\section{$\underline{\text { Reliability }}$}

For reliability purposes, a second observer independently collected data on $25 \%$ of the sessions for child behavior. Kappa, a computational technique that accounts for potential agreement due to chance, was used to estimate percent agreement between observers for child behavior. Adequate percentages of interobserver agreement scores were obtained. For child 
behavior, the mean Kappa coefficient scores for Appropriate behavior were .93 in Classroom 1, .82 in Classroom 2, and .88 in Classroom 3.

The number of agreements divided by the number of agreements plus disagreements was used to calculate observer agreement for teacher behavior. Agreement was calculated for $28 \%$ of the observations. For the teacher behaviors, the following agreement percentages were obtained: descriptive/reflective statement (87\%, range 50\% - 100\%); praise (86\%, range $0 \%$ - 100\%), criticism $(80 \%$, range $0 \%-100 \%)$, questions (85\%, range $25 \%-100 \%)$, direct command (79\%, range $33 \%-100 \%)$, and indirect command (79\%, range 33\% - 100\%) categories. The low percentages of agreement and the large variability within categories reflect behaviors which occurred infrequently. For example, if one coder recorded one instance of a behavior and the reliability coder recorded two instances, the overall reliability for that category is $50 \%$. Thus, the agreement percentages and ranges are variable as a result of the infrequent occurrence of some behaviors. However, it is important to consider that this large variability could have impacted negatively on the accuracy of the behavior observation data.

Procedure

\section{Experimental Design}

A multiple baseline design across three classrooms was used to evaluate (a) the effectiveness of adapting PCIT to train teachers in Head Start, and (b) the potential added benefit of direct coaching over didactic training alone. In Classrooms 1 and 3, the phases were (a) baseline, (b) didactic, and (c) coaching. In Classroom 2, the phases were (a) baseline, (b) didactic, and then a repetition of the didactic session was conducted at approximately the same time as the coaching phase was implemented in Classroom 1. This was done to help evaluate if 
there appeared to be treatment effects due to coaching, whether the apparent effects potentially were due to other variables (e.g., contact time, repetition of skills presentation).

Teacher training was conducted in two formats: (a) didactic instruction, and (b) in-vivo coaching. Each training session was conducted in a two-hour period. Originally, two separate 1hour training sessions were to be conducted. However, due to teacher scheduling limitations, a 2hour block that could be conducted on a day that they were required to be at school but children did not attend was preferable to arriving early or staying late at school. Therefore, the training was conducted during a single, 2-hour block for both didactic and coaching sessions. The amount of contact time was equivalent across phases ( 2 hours per phase, per teacher) and across classrooms (4 hours total per teacher).

\section{Baseline}

No training was provided during baseline. The teachers and children were observed during their regular classroom hours. In Classrooms 1 and 2, baseline was in place for 4 weeks. In Classroom 3, baseline was in place for 7 weeks. The decisions for ending baseline and beginning the experimental conditions were based on scheduling availability and time.

\section{Didactic Training}

One didactic training session for each of the teaching teams from Classrooms 1 and 3 was conducted. The teaching team in Classroom 2 had two didactic sessions (to control for contact time, as this team was not involved in the coaching condition). To train the skills, the primary investigator (a) provided handouts for the teachers, (see Appendices H, I, and J), (b) defined the skills and provided examples, (c) modeled the skills, and (d) conducted role-plays. Each didactic session lasted 2 hours and was scheduled outside of class time. The teaching team from each class attended this session together. Because the session was scheduled outside class time, data 
collection did not need to be stopped at any time for the didactic training. The didactic condition was in place in Classroom 1 for 3 weeks, in Classroom 2 for 7 weeks, and in Classroom 3 for 2 weeks.

Coaching

Each teacher in Classroom 1 and Classroom 3 received a 2-hour coaching training session. There was only time for one coaching block on any given day. Therefore, the two coaching sessions for each classroom were conducted on consecutive days. One teacher would volunteer to be coached on the first day and the second teacher volunteered to be coached on the second day. Data were not collected on the days that coaching occurred. Data collection resumed on the day following the two coaching days. To keep coders unaware of the experimental conditions, they were provided with false reasons for not collecting data on the days in which coaching was to occur (e.g., a teacher was planning to be absent, the experimenter was planning to meet with them). The coaching condition was in place in Classroom 1 for 4 weeks. The coaching condition was in place in Classroom 3 for 2 weeks.

For coaching purposes, the teacher wore a hearing-aid device called a bug-in-ear, a wireless microphone system. This enabled the investigator to sit at the back of the room while coaching the teacher. Coaching was conducted initially in an analog situation, in which the teacher was interacting with only one or two students. After approximately 15 minutes, coaching progressed to situations in which the teacher was interacting with the entire class. Each coaching session lasted 2 hours. Coaching was conducted in the manner described in the introduction of this manuscript. For example, the experimenter may have stated "Okay, the child by the blocks is not cleaning up right now, so I would like you to walk over and give a direct command, such as 'Please put the blocks in the box' to her." After the teacher followed through with the instruction, 
the experimenter might have stated, "Nice job giving a concise direct command." Following child compliance, then, the experimenter might state, "Because she has complied, please say 'Thank you for listening.'” If other children were cleaning up also, then the experimenter may have directed the teacher to provide attention to other children who were cleaning as well. The primary investigator typically sat on a chair in the corner of the room, away from the children and the classroom activities.

\section{$\underline{\text { Classroom Observation }}$}

Classroom observations were conducted Mondays through Thursdays, as children did not attend Head Start on Fridays. On average, data were collected 3 to 4 days per week with approximately four 10-minute child behavior observations and two 10-minute teacher observations per day. Observation periods were divided into two units: teacher behavior observation and child behavior observation. Coding time was limited to approximately 1 hour to accommodate the approximate amount of structured activity time in each Head Start classroom. Because the classroom activities were variable, observers were given the flexibility to determine the order in which to observe child and teacher behaviors. For example, the observer could have coded the teacher aide two consecutive times if the teacher was engaged in an activity that did not involve interaction with the children. Likewise, if a child was not in the room, the coder observed teacher behavior until the child returned to the room, when possible.

Child behavior. Child behaviors were recorded on the classroom coding system during 10-minute observation periods. The number of sessions recorded per day was approximately four, but this varied due to the classroom activities or child availability (i.e., sometimes a child was removed from the room for an extended time during the observation for another activity such as speech therapy). Observations were made on a 10-second observe, 5-second record basis, 
alternating between children. A prerecorded audiotape played on dual jack earphones (for interobserver reliability purposes) cued the intervals.

Teacher behavior. Teacher sessions were 5-minute, real-time coding intervals. Approximately two sessions per teacher were recorded each day. The observer selected one teacher to observe for a 5-minute period. The teacher who primarily was interacting with the children was selected for observation (e.g., leading the circle time, engaging in instructional activities, supervising free-play activities). The second teacher was observed during times when she was engaged directly with the children. To record teacher behaviors, an observer repeated the statements made by the teacher into a hand-held tape recorder for coding at a later time. This procedure was implemented when acoustic difficulties made obtaining and maintaining reliability problematic.

Results

\section{$\underline{\text { Child Behavior }}$}

It was expected that child participants' behaviors would be appropriate for a greater percentage of the intervals in the didactic condition than in baseline, and for an even greater percentage in the coaching than in the didactic condition. This hypothesis was not supported, as no detectable trend was evident across conditions for the child participants across classrooms. Results of the behavior observations for child participants are depicted in Figure 1. Each data point represents the average of two behavior observation sessions that were conducted on the same day. Results of the SESBI are presented in Table 1.

$\underline{\text { Behavior Observations }}$

Classroom 1. Jill and Tom were the child participants in Classroom 1. For Jill, rates of appropriate behavior during baseline ranged from $55 \%$ to $100 \%$, with an overall condition mean 
of $88 \%$. In the didactic condition, her rates of appropriate behavior ranged from $65 \%$ to $100 \%$, with an overall didactic condition mean of $90 \%$. In the coaching condition, Jill's rates of appropriate behavior ranged from $70 \%$ to $100 \%$, with an overall coaching condition mean of $97 \%$.

For Tom, rates of appropriate behavior during baseline ranged from 5\% to $100 \%$, with an overall condition mean of $88 \%$. In the didactic condition, his rates of appropriate behavior ranged from $50 \%$ to $100 \%$, with an overall didactic condition mean of $88 \%$. In the coaching condition, Tom's rates of appropriate behavior ranged from $65 \%$ to $100 \%$, with an overall coaching condition mean of $93 \%$.

In summary, Jill's rates of appropriate behavior were $88 \%, 90 \%$, and $97 \%$, in the baseline, didactic, and coaching conditions, respectively. Tom's rates of appropriate behavior were $88 \%, 88 \%$, and $93 \%$. These rates of appropriate behavior demonstrate the trend that was expected, with the percent appropriate behavior being greatest in the coaching condition.

Classroom 2. Jack and Alex were the child participants in Classroom 2. For Jack, rates of appropriate behavior during baseline ranged from $20 \%$ to $100 \%$, with an overall condition mean of $87 \%$. In the didactic condition, his rates of appropriate behavior ranged from $20 \%$ to $100 \%$. Following the first didactic session, Jack's overall condition mean was $87 \%$. Jack's overall mean following the didactic retraining session was $69 \%$. Including the entire didactic condition, Jack's overall didactic condition mean was $78 \%$.

For Alex, rates of appropriate behavior during baseline ranged from $40 \%$ to $100 \%$, with an overall condition mean of $94 \%$. In the didactic condition, his rates of appropriate behavior ranged from $65 \%$ to $100 \%$. Following the first didactic session, Alex's overall condition mean 
was $95 \%$. Alex's overall mean following the didactic retraining session was $96 \%$. Including the entire didactic condition, Alex's overall didactic condition mean was 95\%.

In summary, the teachers received didactic training only to clarify whether changes in teacher behavior in other classrooms were due to coaching rather than repeated exposure to skills. Jack's rate of appropriate behavior remained the same from baseline through the didactic condition prior to the teacher retraining (87\%). Following the retraining, Jack's appropriate behavior decreased to $69 \%$. Therefore, his overall didactic condition mean of appropriate behavior $(78 \%)$ was lower than the baseline mean. In contrast, Alex's appropriate behavior was $94 \%$ during baseline and increased very slightly to $95 \%$ in the didactic condition. Therefore, no clear pattern of appropriate behavior was evident for the child participants in Classroom 2.

Classroom 3. Kathy and Sam were the child participants in Classroom 3. For Kathy, rates of appropriate behavior during baseline ranged from $45 \%$ to $100 \%$, with an overall condition mean of $91 \%$. In the didactic condition, her rates of appropriate behavior ranged from $95 \%$ to $100 \%$, with an overall didactic condition mean of $99 \%$. In the coaching condition, Kathy's rates of appropriate behavior ranged from $70 \%$ to $100 \%$, with an overall coaching condition mean of $96 \%$.

For Sam, rates of appropriate behavior during baseline ranged from $15 \%$ to $100 \%$, with an overall condition mean of $84 \%$. In the didactic condition, his rates of appropriate behavior ranged from $85 \%$ to $100 \%$, with an overall didactic condition mean of $96 \%$. In the coaching condition, Sam's rates of appropriate behavior ranged from $35 \%$ to $100 \%$, with an overall coaching condition mean of $90 \%$.

In summary, Kathy's rates of appropriate behavior were $91 \%, 99 \%$, and $96 \%$, in the baseline, didactic, and coaching conditions, respectively. Tom's rates of appropriate behavior 
were $84 \%, 96 \%$, and $90 \%$. These rates do not demonstrate the trend that was expected, as the rates of appropriate behavior were highest during the didactic condition.

\section{Sutter-Eyberg Child Behavior Inventory}

It was expected that teacher ratings of child behavior on the SESBI would be lower in the didactic condition than during baseline, and would be the lowest during the coaching condition. This hypothesis was not supported, as no detectable trend was evident across conditions for the child participants across classrooms.

Classroom 1. Jill and Tom were the child participants in Classroom 1. On the selection SESBI, Jill received an intensity/problem score of 136 / 7 and 125 / 11 from Teachers 1 and 2, respectively. On the baseline SESBI, Jill received 154 / 11 and 134 / 6 from Teachers 1 and 2, respectively. At the termination of the didactic condition, Jill received 155 / 9 and 142 / 11 . Following Coaching, Jill received 174 / 19 on the SESBI from Teacher 2. Data from Teacher 1 were not available.

On the selection SESBI, Tom received an intensity/problem score of 208 / 26 and 95 / 18 from Teachers 1 and 2, respectively. On the baseline SESBI, Tom received 204 / 16 and 214 / 23 from Teachers 1 and 2, respectively. At the termination of the didactic condition, Tom received 193 / 2 and 157 / 13. Following Coaching, Tom received 210 / 24 on the SESBI from Teacher 2. Data from Teacher 1 were not available.

In summary, Jill received nearly identical scores on the SESBI across the baseline and didactic conditions from Teacher 1 . Teacher 1 scores were not available for the coaching condition. From Teacher 2, Jill received increasingly higher ratings on both the intensity and problem scores of the SESBI across the baseline, didactic, and coaching conditions. Tom received a lower intensity and problem score in the didactic condition that during baseline. 
Teacher 1 scores were not available for the coaching condition. From Teacher 2, Tom received the lowest scores on the SESBI during the didactic condition. Contrary to the expected outcome, the lowest scores were obtained during the coaching condition.

Classroom 2. Jack and Alex were the child participants in Classroom 2. On the selection SESBI, Jack received an intensity/problem score of 204 / 28 from Teacher 3. On the baseline SESBI, Jack received 74 / 4 and 227 / 30 from Teachers 3 and 4, respectively. At the termination of the didactic condition, Jack received $180 / 25$ and $190 / 27$.

On the selection SESBI, Alex received an intensity/problem score of 77 / 5 from Teacher 3. Teacher 4 did not complete the SESBI for purposes of selection. On the baseline SESBI, Alex received 183 / 21 and 97 / 9 from Teachers 3 and 4, respectively. At the termination of the didactic condition, Alex received 90 / 5 and $126 / 11$.

In summary, Jack received both a higher intensity and a higher problem score in the didactic condition than in the baseline condition from Teacher 3 . In contrast, Jack received a lower intensity and a lower problem score in the didactic condition than in the baseline condition from Teacher 4. Similarly, Alex received a lower intensity and a lower problem score in the didactic condition than in the baseline condition from Teacher 3 . In contrast, he received both a higher intensity and higher problem score in the didactic condition than in the baseline condition from Teacher 4. Therefore, no clear pattern of SESBI scores was evident across child participants from the two teachers in Classroom 2.

Classroom 3. Kathy and Sam were the child participants in Classroom 3. On the selection SESBI, Kathy received an intensity/problem score of 75 / 20 and 46 / 8 from Teachers 5 and 6, respectively. On the baseline SESBI, Kathy received 112 / 12 and 60 / 0 from Teachers 5 and 6, respectively. At the termination of the didactic condition, Kathy received 124 / 10 and 99 / 0. 
Following Coaching, Kathy received 81 / 0 on the SESBI from Teacher 6. Data from Teacher 5 were not available.

On the selection SESBI, Sam received an intensity/problem score of $70 / 11$ and $50 / 7$ from Teachers 5 and 6, respectively. On the baseline SESBI, Sam received 127 / 19 and 98 / 1 from Teachers 5 and 6, respectively. At the termination of the didactic condition, Sam received 133 / 11 and 122 / 4. Following Coaching, Sam received 111 / 9 on the SESBI from Teacher 6. Data from Teacher 5 were not available.

In summary, Kathy received the lowest ratings on both the intensity and the problem scores from both Teacher 5 and Teacher 6 during the baseline condition. Sam received nearly identical scores on the SESBI across the baseline and didactic conditions from Teacher 5. From Teacher 6, Sam received the lowest scores on the SESBI during the didactic condition. Contrary to the expected outcome, the lowest scores were obtained during the coaching condition.

\section{Teacher Behavior}

Originally, teacher behavior was going to be represented graphically for a positive composite, which reflected a combination of descriptive/reflective statements and labeled praises. However, more information could be gleaned from graphing praise (including both labeled and unlabeled) separately from descriptive/reflective statements. Also, as originally proposed, criticisms and the direct command percentages were graphed. In addition, questions were graphed on the same graph as criticisms. It was expected that the frequency of descriptive/reflective statements and praise would increase in the didactic condition, and then again in the coaching condition. In contrast, it was expected that the frequency of criticisms and questions would decrease in the didactic condition, and then again in the coaching condition. Additionally, the percentage of direct commands was expected to increase in the didactic 
condition, and increase more in the coaching condition. These hypotheses were not supported, as no detectable trends were evident across conditions for the teachers across classrooms. Results of the behavior observations for teachers are depicted in Figures 2 - 10. As mentioned previously, there was an average of two teacher observation sessions, per teacher, each day.

\section{$\underline{\text { Classroom } 1}$}

The teacher participants in Classroom 1 will be referred to as Teacher 1 and Teacher 2. The primary teacher is Teacher 1 and the teacher aide is Teacher 2. Descriptive/reflective statements, praise, criticisms, and questions for Teacher 1 are presented in Figure 2 and for Teacher 2 in Figure 3. The direct command percentages are presented in Figure 4.

Teacher 1. The mean frequency of descriptive/reflective statements for Teacher 1 was 7 during baseline, 11 during the didactic condition, and 14 during the coaching condition. The mean frequency of praises was 1 during baseline, 1 during the didactic condition, and 3 during the coaching condition. The mean frequency of criticisms was 2 during baseline, 1 during the didactic condition, and 3 during the coaching condition. The mean frequency of questions was 5 during baseline, 11 during the didactic condition, and 7 during the coaching condition. The mean percent of direct commands was $72 \%$ during baseline, $64 \%$ during the didactic condition, and $52 \%$ during the coaching condition.

Teacher 2. The mean frequency of descriptive/reflective statements for Teacher 2 was 9 during baseline, 12 during the didactic condition, and 13 during the coaching condition. The mean frequency of praises was 2 during baseline, 2 during the didactic condition, and 3 during the coaching condition. The mean frequency of criticisms was 1 during baseline, 2 during the didactic condition, and 1 during the coaching condition. The mean frequency of questions was 11 during baseline, 15 during the didactic condition, and 11 during the coaching condition. The 
mean percent of direct commands was $31 \%$ during baseline, $44 \%$ during the didactic condition, and $39 \%$ during the coaching condition.

In summary, both teachers in Classroom 1 demonstrated a greater number of descriptive/reflective statements, on average, in the didactic condition over the baseline, and the greatest number in the coaching condition. This was consistent with the expected trend for this skill, although greater change, as seen in PCIT, was expected. Likewise, both teachers evidenced more praise in the didactic condition than in the baseline, and the most praise in the coaching condition. However, no clear pattern was revealed for either teacher in their use of criticisms and questions.

\section{$\underline{\text { Classroom } 2}$}

The teacher participants in Classroom 2 will be referred to as Teacher 3 and Teacher 4. The primary teacher is Teacher 3 and the teacher aide is Teacher 4. Descriptive/reflective statements, praise, criticisms, and questions for Teacher 3 are presented in Figure 5 and for Teacher 4 in Figure 6. The direct command percentages are presented in Figure 7.

Teacher 3. The mean frequency of descriptive/reflective statements for Teacher 3 was 14 during baseline, 11 during the initial didactic training, and 17 following the didactic re-training. The mean frequency of praises was 1 during baseline, 1 during the initial didactic training, and 1 following the didactic re-training. The mean frequency of criticisms was 3 during baseline, 2 during the initial didactic training, and 2 following the didactic re-training. The mean frequency of questions was 10 during baseline, 9 during the initial didactic training, and 9 following the didactic re-training. The direct command percentages were $48 \%$ during baseline, $49 \%$ during the initial didactic training, and 55\% following the didactic re-training. 
Teacher 4 . The mean frequency of descriptive/reflective statements for Teacher 4 was 5 during baseline, 6 during the initial didactic training, and 6 following the didactic re-training. The mean frequency of praises was 1 during baseline, 3 during the initial didactic training, and 1 following the didactic re-training. The mean frequency of criticisms was 1 during baseline, 1 during the initial didactic training, and 1 following the didactic re-training. The mean frequency of questions was 6 during baseline, 6 during the initial didactic training, and 6 following the didactic re-training. The mean percent of direct commands was $60 \%$ during baseline, $48 \%$ during the initial didactic training, and $63 \%$ following the didactic re-training.

In summary, Teacher 3 demonstrated a greater use of descriptive/reflective statements following the didactic retraining. However, this pattern was not evident in a change in the use of praise, criticisms, or questions. Also, with the exception of a small increase in the use of praise in the didactic condition prior to retraining, Teacher 4 did not demonstrate changes in skill frequency across conditions or the didactic retraining. Therefore, it does not seem that repetition of the skills in a didactic format, as was done in this study, is sufficient to evoke behavior change.

\section{Classroom 3}

The teacher participants in Classroom 3 will be referred to as Teacher 5 and Teacher 6 . The primary teacher is Teacher 5 and the teacher aide is Teacher 6 . Descriptive/reflective statements, praise, criticisms, and questions for Teacher 5 are presented in Figure 8 and for Teacher 6 in Figure 9. The direct command percentages are presented in Figure 10.

Teacher 5. The mean frequency of descriptive/reflective statements for Teacher 5 was 11 during baseline, 9 during the didactic condition, and 11 during the coaching condition. The mean frequency of praises was 1 during baseline, 2 during the didactic condition, and 7 during the 
coaching condition. The mean frequency of criticisms was 1 during baseline, 1 during the didactic condition, and 1 during the coaching condition. The mean frequency of questions was 11 during baseline, 10 during the didactic condition, and 8 during the coaching condition. The mean percent of direct commands was $52 \%$ during baseline, $61 \%$ during the didactic condition, and $32 \%$ during the coaching condition.

Teacher 6. The mean frequency of descriptive/reflective statements for Teacher 6 was 8 during baseline, 8 during the didactic condition, and 12 during the coaching condition. The mean frequency of praises was 1 during baseline, 1 during the didactic condition, and 3 during the coaching condition. The mean frequency of criticisms was 1 during baseline, 1 during the didactic condition, and 1 during the coaching condition. The mean frequency of questions was 13 during baseline, 13 during the didactic condition, and 14 during the coaching condition. The mean percent of direct commands was $58 \%$ during baseline, $69 \%$ during the didactic condition, and $49 \%$ during the coaching condition.

In summary, no clear pattern was discernible in the use of descriptive/reflective statements for either teacher in Classroom 3. However, both teachers demonstrated a greater frequency of praise in the coaching condition than in the baseline and didactic conditions. Both teachers had a mean of 1 for criticism across all three conditions. Thus, no changes could be seen due to a basal effect. Teacher 5 demonstrated a lower frequency of questions in the coaching sessions than in either the baseline or didactic. In contrast, Teacher 6 demonstrated a higher frequency of questions in the coaching condition than in either the baseline or didactic. Therefore, both teachers had a greater frequency of praise in the coaching condition, but clear patterns were not evident across the other skills. 


\section{$\underline{\text { Teacher Satisfaction }}$}

The highest score (i.e., 50) on the teacher satisfaction questionnaire indicates the greatest satisfaction with the behavior management program being evaluated. The teacher satisfaction scores per condition per teacher are presented in Table 2.

\section{$\underline{\text { Classroom } 1}$}

In Classroom 1, Teacher 1 reported a satisfaction score 36 on the didactic and did not complete the questionnaire following coaching. Teacher 2 reported a satisfaction score of 42 on the didactic and 41 on the coaching.

\section{Classroom 2}

In Classroom 2, Teacher 3 reported a satisfaction score of 35 on the didactic and was in the classroom that did not receive the coaching condition. Teacher 4 reported a satisfaction score of 36 on the didactic and was in the classroom that did not receive the coaching condition.

\section{$\underline{\text { Classroom } 3}$}

In Classroom 3, Teacher 5 reported a satisfaction score of 32 on the didactic and 27 on the coaching. Teacher 6 reported a satisfaction score of 39 on the didactic and 39 on the coaching.

\section{Discussion}

The reasons for conducting this study were twofold. The first goal was to evaluate the effectiveness of adapting PCIT to train classroom teachers in behavior management. The second goal was to evaluate the added benefit of direct coaching over didactic training. PCIT skills were introduced to six classroom teachers. A multiple baseline design across classrooms was implemented, in which teaching teams in Classrooms 1 and 3 received training in the skills used in PCIT in a 2-hour didactic session for the first experimental phase and through a 2-hour direct 
coaching session in the second experimental phase. In Classroom 2, the teaching team received training in a 2-hour didactic session, which was then repeated at approximately the same time as the coaching was introduced in Classroom 1.

The primary method of evaluation was visual analysis of graphic representations of the behavior observations for both child and teacher behaviors. The child behaviors were coded as Appropriate or Inappropriate. The teacher behaviors coded were the behavior management skills in which they had been instructed (i.e., description/reflection, labeled praise, criticism, direct command, and indirect command). Additionally, teachers completed a paper and pencil measure to provide data reflecting their perceptions of child behavior and a paper and pencil measure reflecting teacher satisfaction with the behavior management training in each condition.

Overall, the findings of this study did not support the expected outcomes. There were no discernable patterns of behavior change across children. Also, there was not evidence that the 2hour coaching training provided added benefit to the 2-hour didactic training for teaching new skills to teachers. However, these results must be interpreted with caution, and the following limitations of the study must be taken into consideration.

\section{$\underline{\text { Limitations and Future Directions }}$}

\section{$\underline{\text { Intervention Implementation }}$}

There are several likely limitations with the manner in which the behavior management skills were taught that may have impacted the findings of this study. In general, the amount of information provided to the teachers was large, and it was provided in a short time frame. This was not consistent with the way that traditional PCIT is implemented.

Typically, PCIT is taught in two separate phases: first, the selective attention skills are taught (i.e., child-directed interaction), and second, the compliance skills are taught (i.e., parent- 
directed interaction). The skills in each of these phases are taught over the course of 12 sessions, during which didactic training, rehearsal, modeling, and coaching occur. Also, the compliance skills are not taught until mastery of the selective attention and tactical ignoring skills is exhibited. Hence, parents must demonstrate performance of the initial skills prior to receiving training in the compliance skills.

In the classroom, there was concern that the teachers would be resistant to having multiple sessions for both didactic and coaching trainings. Therefore, the trainings were condensed to 2-hours each. Given the findings of this study, it seems that there was too much information provided in the training given the time limit. Perhaps a different finding would have been obtained had the 2-hour training been broken into two, 1-hour sessions. Some of the teachers exhibited changes in some of the skills, however, these were not seen across teachers or across skills. Also, there was no evaluation of mastery of the skills. Hence, training ended regardless of whether the teachers understood or were able to exhibit the strategies that were taught. Anecdotally, it was apparent that the teachers used the skills more toward the end of the 2-hour coaching training than in the beginning. However, data were not collected during the coaching, and data that were collected subsequent to the coaching did not illustrate the greater use of the behavior management skills.

It is interesting that Teacher 3 exhibited an increase in descriptive/reflective statements and praise immediately following the didactic retraining. This occurrence may suggest a need for repeated exposure to skills in order to obtain teacher behavior change (Anderson \& Kratochwill, 1988). Hence, it may be important to evaluate the use of repeated didactic trainings in comparison with repeated coaching trainings to decipher repetition effects on skill acquisition. 
Overall, there were several concerns with the implementation of the training of the behavior management skills. In contrast to PCIT, a large amount of information was covered in a singular 2-hour time block in both the didactic and coaching conditions. Further, there was no opportunity to expand training if the use of the skills was not exhibited, as is done in PCIT. In summary, the modifications of PCIT made for the purposes of this study were so large that the effectiveness of this strategy for training teachers was not truly evaluated.

\section{Experimental Design}

This study was conducted according to a schedule based on time and availability of those involved (i.e., teachers, research assistants, experimenter). A more powerful design would be a true multiple baseline experiment, in which condition changes are data-based decisions. Further, the procedure would be flexible, such that changes could be made based on the data rather than adhering to a pre-determined treatment package.

In addition to the lack of adherence to the principles of single subject research, another problem in the design is noted. There were several questions addressed by this research. One goal of this study was to evaluate whether adapting PCIT to the classroom was effective for changing child behavior. However, this could not be evaluated because the teachers did not learn to implement the skills. In order to evaluate the effectiveness of an adapted version of PCIT, treatment integrity criteria must be established for the teacher behaviors. Once adherence to these criteria is obtained, then the utility of implementing the PCIT skills in the classroom to modify child behavior can be evaluated.

\section{$\underline{\text { Participant Selection }}$}

The participant selection procedure is one that has been used previously in similar studies (e.g., Bahl et al., in press; Funderburk, 1989). As in the previous studies, the participants selected 
in this project were those who received the highest ratings over all other children in the class on two teacher report measures (i.e., the behavior rating scale and the SESBI). However, only two of the participants who were selected for this study had clinically significant behavior problems at the time of selection, according to the SESBI. In fact, Tom received clinically significant scores from each teacher once, and Jack and Alex received clinically significant scores one time each. Otherwise, the selected child participants did not have clinically significant scores on either the intensity or the problem scale throughout the duration of the study. Therefore, although the child may have had the highest ratings in comparison to other children in the class, the behaviors reported by the teachers were not in the clinically significant range. This is significant when considering the limitations as a result of the ceiling effects that were observed.

\section{$\underline{\text { Ceiling Effects }}$}

Although the children were selected because they received elevated ratings on two teacher report measures of disruptive behavior, the behavior observations suggest that the majority of the child participants generally were well behaved. Overall, the mean rates of appropriate behavior across conditions were above $83 \%$ for five of the six child participants and above $75 \%$ for the sixth child participant. Hence, there was little room for behavior improvements. To remedy this limitation, future studies could benefit from including children who are referred for behavior problems. Previous studies that have used clinically referred samples (e.g., McNeil et al., 1991) reported lower rates of appropriate behavior.

\section{$\underline{\text { Teacher Motivation }}$}

There are a few explanations that have not been explored that may have factored into the lack of systematic behavior change across teachers. As stated previously, ceiling effects were a limitation in this study. In addition to these being of concern for evaluation of the child behavior, 
they also may have impacted the teachers. Given that the mean rates of appropriate behavior were higher than $83 \%$ for five of the six child participants, it is unlikely that the teachers were motivated to learn new skills for behavior management. If, however, the children were appropriate for a much lower percentage of the intervals, the teachers may have been negatively reinforced for using the skills by the decrease in inappropriate behaviors. As stated previously, the use of a clinically referred sample would have improved this limitation.

In PCIT, parents who attend treatment are those who state that they want to learn strategies to improve their child's behavior. However, the teachers who participated in this study were not individuals who stated that they wanted to learn new behavior management strategies. Hence, we did not target teachers who necessarily wanted to change their behavior. Although the teachers' reasons for participation were unknown to the experimenter, it is possible that they participated to earn the monetary compensation. The monetary compensation was provided contingent on completion of the study, but other requirements were not linked to earning the money. Therefore, the monetary compensation was not established to serve as a reinforcer for behavior change. It would be interesting for future studies to provide monetary rewards contingent on skill acquisition.

\section{$\underline{\text { Missing Data }}$}

Due to uncontrolled circumstances, teacher report ratings were missing from one teacher in each of the classrooms during one of the conditions. In Classroom 1, the experimenter was unaware that Teacher 1 was leaving town before the end of the school year. Therefore, the SESBI and the teacher satisfaction data were not available. In Classroom 2, Teacher 4 did not complete the SESBI for child participant selection purposes. Therefore, the SESBI ratings from Teacher 3 only were used for selection purposes for children in Classroom 2. In Classroom 3, 
there was miscommunication between the experimenter and the research assistant, and the SESBI ratings from Teacher 5 were not collected.

\section{Classroom Coding System}

It is likely that the classroom coding system used for child behavior observations was not sensitive to the behavior concerns reported by the teachers on the teacher report measures. In this study, the children who received the highest ratings on the teacher report measures were not necessarily exhibiting high levels of inappropriate behavior, according to the coding system definitions. It is important, however, to consider the range of percentages of appropriate behavior observed for several child participants. Throughout the majority of observations, the children were engaging in appropriate behavior, but on occasion, they would be observed to engage in appropriate behavior for fewer than $50 \%$ of the intervals. This suggests that the children may have engaged in episodic instances of inappropriate behavior. These episodes may have impacted the teacher ratings on the teacher report measures, but the behavior observation system was not sensitive to these occurrences. Finally, it is possible that child behavior did not demonstrate change because the teachers interactions with the targeted children were not evaluated specifically. Therefore, a more effective means of evaluating treatment effects on child behavior may be to identify and record the occurrence of specific target behaviors for each identified child.

\section{Sutter-Eyberg Student Behavior Inventory Variability}

The variability in the scores that teachers reported for child participants was surprising. It is difficult to understand the unique behavior concerns that were represented by the fluctuating scores across classrooms. Therefore, these data do not provide information that help illuminate the child behaviors occurring in the classroom. Perhaps a more effective way to obtain teacher 
perceptions of child behavior would be to target specific behaviors that the teacher reports are of concern. Then, changes in that specific behavior can be used as a dependent measure of treatment effectiveness.

\section{$\underline{\text { Teacher Satisfaction }}$}

Because coaching in the classroom was a new method of training behavior management skills to teachers, the satisfaction measure was of great interest. It was possible that this type of training would be too intrusive to implement during the regular school day. Thus, reconsideration of the adaptability of coaching to the classroom would be needed.

The teacher satisfaction ratings were available for comparison across the didactic and coaching conditions for three teachers. Of these three teachers, two reported lower satisfaction for the coaching method of training, and one reported equivalent scores for the didactic and coaching methods. These scores suggest that the teachers were either equally satisfied or less satisfied with the coaching method of training behavior management skills. Interestingly, however, the two teachers who reported the lower satisfaction scores for the coaching method than the didactic wrote comments onto the satisfaction questionnaire. The two comments were the following:

"I would need a longer time to process info along with more feedback from the trainer." (Teacher 5)

“I knew many of the techniques, however I didn't implement them on a consistent basis. The constant reminding helped me to be more consistent. I feel that a couple more days with (the consultant) would help me be even more confident. I have seen a big difference in 'Tom' within the past couple of days. The one to one interactions with him have definitely helped." (Teacher 2). 
These comments provide insight that the coaching methodology, per se, was not an issue. Rather, the teachers commented that the brief time in which this strategy was of concern. Therefore, further research evaluating the effectiveness of coaching as a method of training behavior management skills is warranted.

\section{Coaching Integrity Checklist}

The information provided by the coaching integrity checklist is limited. This checklist was based on the use of certain techniques for coaching parents, as identified by Hembree-Kigin and McNeil (1995). The strategies that are targeted by the coaching integrity checklist are important for the quality of coaching that is conducted. That is, it is ensured that the coaching sessions focused on the appropriate skills that the teachers used and the overall interaction was positive. However, there was no information gained or limit set regarding the amount of time devoted to each of the skills, regarding the progression of the coaching from an analog situation to the entire class, or regarding the directiveness of the coaching to teach the skills initially. These are a few examples of information that may have been useful in identifying reasons that the teachers did not acquire the selected skills. It is important that further evaluation of the content of coaching be conducted in order to evaluate the efficacy of this training strategy for classroom teachers.

\section{Therapist Characteristics}

The experimenter was the only person in this study who provided the didactic and coaching training sessions. It is possible that the lack of results is due to individual therapist characteristics. Although treatment integrity criteria were established, these were designed to evaluate the content of the treatment, but individual differences could not be controlled. Because there was not a comparison therapist, the possibility that therapist variables impacted the findings 
cannot be evaluated. It would be beneficial if future research used multiple therapists to evaluate potential differences due to individual differences.

\section{$\underline{\text { Evaluation of Teacher Skills }}$}

Although there were many skills taught during the didactic and coaching training sessions, the use of each of them was not evaluated. In particular, the compliance components were largely ignored, with the exception of the evaluation of the percent of direct commands. That is, the teachers' use of two-choices statements or timeouts were not observed and recorded. In addition, some strategies of selective attention and tactical ignoring, such as the ignoring signal, were not observed. Although there are many variables of interest, it is difficult to examine each of these in a single study. It may be more effective to conduct smaller scope studies that hone in on the training and evaluation of fewer behavior management strategies.

Dyadic Parent-child Interaction Coding System. It is important to consider whether the DPICS was an appropriate system to use to evaluate teacher behavior change. The DPICS was designed to evaluate an intensive, analog interaction between one parent and a single child in a controlled environment (i.e., a clinic setting). In the classroom, teachers were evaluated during the usual classroom activities. Although efforts were made to observe the teachers at the same time for each observation, the nature of the classroom is such that a variety of activities occurred during the coding period, and these activities were not consistent from day to day. That is, observations may have been conducted during whole-class center activities, individualized table activities, mealtimes, or teacher-led group times, to name a few. Therefore, variability in the data may reflect not only inconsistencies in teacher behaviors, but also inconsistencies in classroom activities. 
Additionally, consideration should be given to the specific behaviors that were evaluated on the DPICS in this study. Given that the classroom environment differs greatly from the analog, clinic setting, the targeted behaviors may need to be evaluated differently. For example, it should be expected that teachers use questions or indirect commands, and that these may be used appropriately. However, the DPICS was not sensitive to whether questions were contextually appropriate (e.g., "Did you bring back the book you borrowed?" "Do you need another piece of paper?") or provided in a way such that a descriptive/reflective statement could have been used (e.g., "Is that a house you painted?"). Also, it may be appropriate for teachers to use indirect commands throughout the day, particularly when children generally are compliant with established classroom routines (e.g., "Remember your job."). Finally, the DPICS was used to code teacher behaviors that had been audiotaped. Unfortunately, this increased ambiguity in many of the teacher verbalizations that could have been coded more easily if other contextual cues were available. For example, it sometimes was difficult to determine whether a statement was used as an indirect command (e.g., "All the blocks are spilled out, Jason" and the teacher wanted that child to put them away) or as a description (e.g., "All the blocks are spilled out, Jason," a description of that child's activity). Overall, the results of this study have provided data that may be useful in determining baseline rates of the targeted behaviors in a preschool classroom. However, consideration of these limitations may be helpful in the identification of coding methodologies, target skills, and contextual factors that are appropriate to the classroombased research.

\section{$\underline{\text { Summary of Limitations }}$}

In summary, there were several limitations in this study that may be addressed by future research. Future research in the area of the adaptation of PCIT to the classroom may look more 
closely at training a few specific skills at a time, implementing a mastery criterion for skill acquisition, and coaching skills for a longer duration. In addition, improvements in the experimental design (e.g., the use of data-based changes in the provision of treatment, more specific strategies for coaching, modifications in the contextual format in which coaching is conducted, the use of multiple therapists) will allow for an evaluation of the effectiveness of didactic training versus coaching. Finally, using child participants who are clinically referred and evaluating treatment effectiveness by coding a target behavior selected independently for each individual likely will clarify the findings.

\section{Conclusion}

The findings of this study indicated that the treatment was not powerful enough to obtain consistent improvements across teachers. However, the lack of support may be due to several methodological issues that may have interfered with the experimental outcomes. At a conceptual level, this method of training continues to be the next logical step for improving the technology for training teachers. That is, PCIT is an empirically supported parent-training intervention for 2to 7-year olds who are engaging in disruptive behavior. It follows, then, that the behavior management skills would be appropriate for managing disruptive behavior of 2- to 7- year olds in the classroom. In addition, research has supported the effectiveness of coaching and direct feedback over didactic methods of training skills. Hence, modifying this method to accommodate the classroom seems valuable. Unfortunately, the limitations identified in this study impeded a thorough evaluation of the adaptation of PCIT to the classroom or the use of coaching as a method of training teachers. Although the results found in this study did not support the use of a 2-hour training in behavior management skills, in either a didactic or coaching training methodology, these findings have elucidated many research questions to be incorporated in 
future research. In conclusion, it would be valuable for future research to strive to evaluate the effectiveness of adapting PCIT to the classroom, as well as to evaluate the effectiveness of using coaching in the classroom as a means of training behavior management skills to teachers. 


\section{References}

Anderson, T. K., \& Kratochwill, T. R. (1988). Dissemination of behavioral procedures in the schools: Issues in training. In Witt, J. C, Elliott, S. N., \& Gresham, F. M. (Eds.), Handbook of behavior therapy in education. New York: Plenum.

Bahl, A. B., McNeil, C. B., Cleavenger, C. J., Blanc, H. M. \& Bennett, G. M. (in press). Evaluation of a whole-classroom approach for the management of disruptive behavior. Proven $\underline{\text { Practice. }}$

Bergan, J.R. (1977). Behavioral consultation. Columbus, OH: Charles E. Merrill.

Bernal, M. E., Williams, D. E., Miller, W. H., \& Reagor, P. A. (1972). The use of videotape feedback and operant learning principles in training parents in management of deviant children. In R. D. Rubin, H. Festerheim, J. D. Henderson, \& L. P. Ullman, (Eds.), Advances in behavior therapy. New York: Academic Press.

Brandenberg, N. A., Freidman, R. M., \& Silver, S. (1987). The epidemiology of childhood psychiatric disorders: Recent prevalence findings and methodological issues. Tampa: Florida Mental Health Institute, University of South Florida.

Erchul, W. P., \& Martens, B. K. (1997). School consultation: Conceptual and empirical bases of practice. New York: Plenum.

Eyberg, S. M. (1988). Parent Child Interaction Therapy: Integration of traditional and behavioral concerns. Child and Family Behavior Therapy, 10, 33-46.

Eyberg, S. M., Boggs, S., \& Algina, J. (1995). Parent-child interaction therapy: A psychosocial model for the treatment of young children with conduct problem behavior and their families. Psychopharmacology Bulletin, 31, 83-91. 
Eyberg, S. M., \& Matarazzo, R. G. (1980). Training parents as therapists: A comparison between individual parent-child interaction training and parent group didactic training. Journal of Clinical Psychology, 36, 492-499.

Eyberg, S. \& Pincus, D. (1999). Sutter-Eyberg Student Behavior Inventory - Revised Professional Manual. Odessa, FL: Psychological Assessment Resources.

Eyberg, S. \& Robinson, E. A. (1982). Parent-child interaction training: Effects on family functioning. Journal of Clinical Child Psychology, 11, 130-137.

Eyberg, S. \& Robinson, E. A. (1983). Dyadic Parent-Child Interaction Coding System: A manual. Psychological Documents, 13, Ms. No. 2582.

Forehand, R., \& McMahon, R. (1981). Helping the noncompliant child. A clinicians guide to parent training. New York: Guilford.

Funderburk, B. W. (1989). Parent-Child Interaction training with behavior problem children: Maintenance of treatment effects in the school setting. Unpublished doctoral dissertation, University of Florida, Gainesville.

Funderburk, B. W., \& Eyberg, S. M. (1989). Psychometric characteristics of the SutterEyberg Student Behavior Inventory: A school behavior rating scale for use with preschool children. Behavioral Assessment, 11, 297-313.

Foxx, R. M., \& Shapiro, S. T. (1978). The timeout ribbon: A nonexlusionary timeout procedure. Journal of Applied Behavior Analysis, 11, 125-136.

Gutkin, T. B., \& Curtis, M. J. (1990). School-based consultation: Theory, techniques, and research. In T. B. Gutkin \& C. R. Reynolds (Eds.), The handbook of school psychology. 
Hanf, C. A. (1969). A two-stage program for modifying maternal controlling during mother-child (M-C) interaction. Paper presented at the meeting of the Western Psychological Association, Vancouver.

Hawkins, R. P., Peterson, R. F., Schweid, E., \& Bijou, S. W. (1966). Behavior therapy in the home: amelioration of problem parent-child relations with the parent in a therapeutic role. Journal of Experimental Child Psychology, 4, 99-107.

Hembree-Kigin, T. L., \& McNeil, C. B. Parent-Child Interaction Therapy. New York: Plenum.

Ivancic, M. T., Reid, D. H., Iwata, B. A., Faw, G. D., \& Page, T. J. (1981). Evaluating a supervision program for developing and maintaining therapeutic staff-resident interactions during institutional care routines. Journal of Applied Behavior Analysis, 14, 95-107

Kratochwill, T. R. \& Bergan, J. R. (1990). Behavioral consultation in applied settings. An individual guide. New York: Plenum.

McNeil, C. B., Eyberg, S., Eisenstadt, T. H., Newcomb, K., \& Funderburk, B. (1991). Parent-child interaction therapy with behavior problem children: Generalization of treatment effects to the school setting. Journal of Clinical Child Psychology, 20, 140-151.

Moreland, J. R., Schwebel, A. I., Beck, S., \& Wells, R. (1982). Parents as therapists: A review of the behavior therapy parent training literature - 1975 to 1981 . Behavior Modification, $\underline{6,250-276 .}$

Noell, G. H., Witt, J. C., Gilbertson, D. N., Ranier, D. D., \& Freeland, J. T. (1997). Increasing teacher intervention implementation in general education settings through consultation and performance feedback. School Psychology Quarterly, 12, 77-88. 
O’Dell, S. (1974). Training parents in behavior modification: A review. Psychological Bulletin, 81, 418-433.

O’Leary, K. D., O’Leary, S., \& Becker, W. C. (1967). Modification of deviant sibling interaction pattern in the home. Behavior Research and Therapy, 5, 113-120.

Pfiffner, L. J. \& Barkley, R. A. (1990). Educational placement and classroom management. In R. A. Barkley, (Ed.), Attention-deficit hyperactivity disorder: A handbook for diagnosis and treatment (pp. 498-539). New York: Guilford.

Roberts, M. (1979). The effects on the model of being imitated: A review and critique of the literature. JSAS Catalogue of Selected Documents in Psychology, 9, 7-8.

Robinson, E. A., \& Eyberg, S. (1981). The Dyadic Parent-Child Interaction Coding System: Standardization and validation. Journal of Consulting and Clinical Psychology, 49, 249250.

Shapiro, E. S., DuPaul, G. J., Bradley, K. L., \& Bailey, L. T. (1996). A school-based consultation program for service delivery to middle school students with attentiondeficit/hyperactivity disorder. Journal of Emotional and Behavioral Disorders, 4, 73-81.

Sugai, G. M., \& Tindal, G. A. (1993). Effective school consultation: An interactive approach. Pacific Grove, CA: Brooks/Cole.

Sutter, J., \& Eyberg, S. M. (1984). Sutter-Eyberg Student Behavior Inventory. (Available from Sheila Eyberg, Department of Clinical and Health Psychology. University of Florida, Gainesvile, FL 32610.

Vollmer, T. R., Marcus, B. A., \& LeBlanc, L. (1993). Treatment of self-injury and hand mouthing following inconclusive functional analysis. Journal of Applied Behavior Analysis, 27. $331-334$. 
Wahler, R. G., Winkel, G. H., Peterson, R. F., \& Morrison, D. C. (1971). Mothers as behavior therapists for their own children. In A. M. Graziano (Ed.), Behavior therapy with children. Chicago: Aldine-Atherton.

Watson, T. S., \& Robinson, S. L. (1996). Direct behavioral consultation: An alternative to traditional behavioral consultation. School Psychology Quarterly, 11, 267-278.

Webster-Stratton, C. (1981). Videotape modeling. A method of parent education. Journal of Clinical Child Psychology, 93-97.

Webster-Stratton, C., Hollinsworth, T., Kolpacoff, M. (1989). The long-term effectivenss and clinical significance of three cost-effective training programs for families with conductproblem children. Journal of Consulting and Clinical Psychology, 56, 558-566.

Witt, J. C. (1997). Talk is not cheap. School Psychology Quarterly, 12, 281-292.

Witt, J.C., Gresham, F. M., \& Noell, G. H. (1996). What's behavioral about behavioral consultation? Journal of Educational and Psychological Consultation, 7, 327-344. 
Table 1

Sutter-Eyberg Student Behavior Inventory Scores

\begin{tabular}{|c|c|c|c|c|c|c|c|c|}
\hline \multirow[t]{3}{*}{ Class 1} & \multicolumn{4}{|c|}{ Jill } & \multicolumn{4}{|c|}{ Tom } \\
\hline & \multicolumn{2}{|c|}{ Intensity } & \multicolumn{2}{|c|}{ Problem } & \multicolumn{2}{|c|}{ Intensity } & \multicolumn{2}{|c|}{ Problem } \\
\hline & Teacher & Teacher & Teacher & Teacher & Teacher & Teacher & Teacher & Teacher \\
\hline & 1 & 2 & 1 & 2 & 1 & 2 & 1 & 2 \\
\hline Selection & 136 & 125 & 7 & 11 & 208 & 95 & 26 & 18 \\
\hline Baseline & 154 & 134 & 11 & 6 & 204 & 214 & 16 & 23 \\
\hline Didactic & 155 & 142 & 9 & 11 & 193 & 157 & 2 & 13 \\
\hline Coaching & -- & 174 & -- & 19 & -- & 210 & -- & 24 \\
\hline \multirow[t]{4}{*}{ Class 2} & \multicolumn{4}{|c|}{ Jack } & \multicolumn{4}{|c|}{ Alex } \\
\hline & \multicolumn{2}{|c|}{ Intensity } & \multicolumn{2}{|c|}{ Problem } & \multicolumn{2}{|c|}{ Intensity } & \multicolumn{2}{|c|}{ Problem } \\
\hline & Teacher & Teacher & Teacher & Teacher & Teacher & Teacher & Teacher & Teacher \\
\hline & 3 & 4 & 3 & 4 & 3 & 4 & 3 & 4 \\
\hline Selection & 204 & -- & 28 & -- & 77 & -- & 5 & -- \\
\hline Baseline & 74 & 227 & 4 & 30 & 183 & 97 & 21 & 9 \\
\hline Didactic & 180 & 190 & 25 & 27 & 90 & 126 & 5 & 11 \\
\hline \multirow[t]{4}{*}{ Class 3} & \multicolumn{4}{|c|}{ Kathy } & \multicolumn{4}{|c|}{ Sam } \\
\hline & \multicolumn{2}{|c|}{ Intensity } & \multicolumn{2}{|c|}{ Problem } & \multicolumn{2}{|c|}{ Intensity } & \multicolumn{2}{|c|}{ Problem } \\
\hline & Teacher & Teacher & Teacher & Teacher & Teacher & Teacher & Teacher & Teacher \\
\hline & 5 & 6 & 5 & 6 & 5 & 6 & 5 & 6 \\
\hline Selection & 75 & 46 & 20 & 8 & 70 & 50 & 11 & 7 \\
\hline Baseline & 112 & 60 & 12 & 0 & 127 & 98 & 19 & 1 \\
\hline Didactic & 124 & 99 & 10 & 0 & 133 & 122 & 11 & 4 \\
\hline Coaching & -- & 81 & -- & 0 & -- & 111 & -- & 9 \\
\hline
\end{tabular}


Table 2

Teacher Satisfaction Scores

\begin{tabular}{lcc}
\hline Teacher & Didactic & Coaching \\
\hline Teacher 1 & 36 & -- \\
Teacher 2 & 42 & 41 \\
Teacher 3 & 35 & (didactic only) \\
Teacher 4 & 36 & (didactic only) \\
Teacher 5 & 32 & 27 \\
Teacher 6 & 39 & 39 \\
\hline
\end{tabular}




\section{Appendix A}

Child Behavior Coding System Definitions

(a) Appropriate Behavior: The absence of oppositional behaviors. Behavior must be appropriate for the entire 10-second interval. If unsure as to whether behavior was appropriate or oppositional, code Appropriate Behavior.

(b) Oppositional Behavior: Behaviors are coded as Oppositional Behaviors because they are annoying or disruptive to the target child, the teacher, or other children.

Definitions of Oppositional Behaviors:

1. Whining - Words uttered by the child in a slurring, nasal, high-pitched, falsetto voice.

2. Crying - Inarticulate utterances of distress (audible weeping) that may or may not be accompanied by tears.

3. Yelling - Loud screeching, screaming, shouting, or crying. The sound must be loud enough so that it is clearly above the intensity of normal indoor conversation. Not coded during outdoor recess observations.

4. Tantruming - Any combination of whining, yelling, crying, hitting, and/or kicking.

5. Destructiveness - Behaviors in which the child damages or destroys an object or attempts or threatens to damage an object or injure a person. Do not code if it is appropriate within the context of the play situation (e.g., ramming cars in a car crash). Examples of aggression toward persons include fighting, kicking, slapping, hitting, or grabbing an object roughly away from another person, or threatening to do any of the preceding.

6. Negativism - A verbal or nonverbal negative behavior. May be scored when the child makes a statement in which the verbal message may be neutral, but is delivered in a tone of voice that conveys an attitude of "don't bug me," or "don't bother me." Negativism may be expressed in a derogatory, uncomplimentary, or angry manner. Also included are defeatist statements such as "I give up," contradictions of what another person says (e.g., teacher says: "Johnny did a nice job;" child says: "He did not."), and teasing or mocking behaviors or verbalizations.

7. Pathological Self-Stimulation - Repetitive behavior that may be harmful and interfere with a child's ability to attend or complete a task. Examples of pathological self-stimulation include head-banging, thumb-sucking, and masturbation.

8. Demanding Attention - Includes repetitive verbal and nonverbal requests for attention from the teacher or other students (e.g., "Call on me! Call on me! Call on me!). Other behaviors that 
are coded in this category include making faces, making disruptive noises, repetitively tugging on teacher's sleeve, tapping neighbor on the shoulder, waving arms in air, passing notes to another child, and clowning.

9. High-Rate Behavior - Any very physically active, repetitive behavior that has been carried on sufficiently long that it has become disruptive to either the target child or others. Examples include kicking a child's chair repeatedly, drumming on the table loudly, and spinning a pencil on the desk.

10. Talking Out of Order - Any verbalization made in a situation in which the children are clearly expected to be silent unless asked to speak. Talking Out of Order includes whispering to a neighbor, answering a question not directed toward the target child, talking, singing, or humming to oneself, and calling out to another child.

11. Being Out of Area - Coded when the target child without permission leaves the area that he or she is clearly expected to stay in. Examples include standing up when rest of class is seated, leaving desk, approaching the teacher without permission, playing with an attractive toy that is not in the work area in which the child is supposed to be. When coding, be certain that the out of area behavior is inappropriate for the context or classroom norms (e.g., in some classrooms the teacher may not be disturbed if the child spontaneously walks to the teacher's desk if he obviously needs help on a math problem).

12. Cheating - Child borrows another child's work when such behavior is clearly not allowed. Examples include looking at another child's paper during a spelling quiz and copying another child's work.

13. Noncomply: Target child makes no movement toward obeying a direct or indirect teacher command during a 5-second period following the command. The command can be one directed toward the target child individually or a group of children that includes the target child. To be coded, the command must be given during the $1-=$ second observation interval. If the command is fiven near the end of the 10-second observation, continue to watch for 5-seconds to determine whether the child complies.

14. Off Task: Coded if at any point during the 10 -second interval the child is engaging in behavior that does not meet the definition for On Task behavior. The child is considered to be On Task if he or she is (a) attending to the material and the task, (b) making appropriate motor responses (e.g., writing, computing, pasting), and (c) asking for assistance (where appropriate) in 
an acceptable manner. Interacting with the teacher or classmates about academic matters or listening to teacher instructions and directions are considered to be On Task behaviors. The child must remain on task for the full 10-second observation interval. Examples of Off Task include failure to attend to or work on the assigned task, breaking classroom rules (e.g., out of seat, talking out, disturbing others, etc.), laying head on desk passively when there is a task to complete, and daydreaming. If the child is in timeout during the observation interval, he or she is automatically coded as Off Task. 


\section{Appendix B}

\section{Dyadic Parent-Child Interaction Coding System Definitions}

Descriptive Statement: a declarative sentence or phrase that gives an account of the objects or people in the situation or the activity occurring during the interaction

Reflective Statement: a declarative phrase or statement which immediately repeats the child's verbalization. The reflection may be exactly the same words the child said, may contain synonymous words, or may contain some elaboration upon the child's statement, but the basic content must be the same as the child's message.

Labeled Praise: any specific verbalization that expresses a favorable judgment upon an activity, product, or attribute of the child.

Direct Command: a clearly stated order, demand, or direction in declarative form. The statement must be sufficiently specific as to indicate the behavior that is expected from the child.

Indirect Command: an order, demand, or direction for a behavioral response that is implied, nonspecific, or stated in question form.

Criticism: a verbalization that finds fault with the activities, products, or attributes of the child. 


\section{Appendix C}

\section{BEHAVIOR RATING SCALE}

Completed by:

The initials of all children in your class who have received parental consent are listed below. Rate each child's behavior relative to the behavior of children in this class by marking a circle around the appropriate rating.

\begin{tabular}{|c|c|c|c|c|c|c|c|c|c|c|c|c|c|c|c|}
\hline \multirow[b]{3}{*}{1.} & \multicolumn{5}{|c|}{ Outgoing Scale } & \multicolumn{5}{|c|}{ Disruptive Scale } & \multicolumn{5}{|c|}{ Cooperative Scale } \\
\hline & not ve & & erage & & & never & & average & & most & not very & & average & & very \\
\hline & 1 & 2 & 3 & 4 & 5 & 1 & 2 & 3 & 4 & 5 & 1 & 2 & 3 & 4 & 5 \\
\hline 2. & 1 & 2 & 3 & 4 & 5 & 1 & 2 & 3 & 4 & 5 & 1 & 2 & 3 & 4 & 5 \\
\hline 3. & 1 & 2 & 3 & 4 & 5 & 1 & 2 & 3 & 4 & 5 & 1 & 2 & 3 & 4 & 5 \\
\hline 4. & 1 & 2 & 3 & 4 & 5 & 1 & 2 & 3 & 4 & 5 & 1 & 2 & 3 & 4 & 5 \\
\hline 5. & 1 & 2 & 3 & 4 & 5 & 1 & 2 & 3 & 4 & 5 & 1 & 2 & 3 & 4 & 5 \\
\hline 6. & 1 & 2 & 3 & 4 & 5 & 1 & 2 & 3 & 4 & 5 & 1 & 2 & 3 & 4 & 5 \\
\hline 7. & 1 & 2 & 3 & 4 & 5 & 1 & 2 & 3 & 4 & 5 & 1 & 2 & 3 & 4 & 5 \\
\hline 8 . & 1 & 2 & 3 & 4 & 5 & 1 & 2 & 3 & 4 & 5 & 1 & 2 & 3 & 4 & 5 \\
\hline 9. & 1 & 2 & 3 & 4 & 5 & 1 & 2 & 3 & 4 & 5 & 1 & 2 & 3 & 4 & 5 \\
\hline 10. & 1 & 2 & 3 & 4 & 5 & 1 & 2 & 3 & 4 & 5 & 1 & 2 & 3 & 4 & 5 \\
\hline 11. & 1 & 2 & 3 & 4 & 5 & 1 & 2 & 3 & 4 & 5 & 1 & 2 & 3 & 4 & 5 \\
\hline 12. & 1 & 2 & 3 & 4 & 5 & 1 & 2 & 3 & 4 & 5 & 1 & 2 & 3 & 4 & 5 \\
\hline 13. & 1 & 2 & 3 & 4 & 5 & 1 & 2 & 3 & 4 & 5 & 1 & 2 & 3 & 4 & 5 \\
\hline 14 & 1 & 2 & 3 & 4 & 5 & 1 & 2 & 3 & 4 & 5 & 1 & 2 & 3 & 4 & 5 \\
\hline 15. & 1 & 2 & 3 & 4 & 5 & 1 & 2 & 3 & 4 & 5 & 1 & 2 & 3 & 4 & 5 \\
\hline 16. & 1 & 2 & 3 & 4 & 5 & 1 & 2 & 3 & 4 & 5 & 1 & 2 & 3 & 4 & 5 \\
\hline 17. & 1 & 2 & 3 & 4 & 5 & 1 & 2 & 3 & 4 & 5 & 1 & 2 & 3 & 4 & 5 \\
\hline 18. & 1 & 2 & 3 & 4 & 5 & 1 & 2 & 3 & 4 & 5 & 1 & 2 & 3 & 4 & 5 \\
\hline
\end{tabular}

To your knowledge, will any of the children be absent during the scheduled observation periods? 


\section{Appendix D}

\section{Sutter-Eyberg Student Behavior Inventory}

Below are a series of phrases that describe children's behavior. Please (1) circle the number describing how often the behavior currently occurs with this student, and (2) circle either "yes" or "no" to indicate whether the behavior is currently a problem.

How often does this occur with this student?

1. Dawdles in obeying

$\begin{array}{llll}1 & 2 & 3 & 4\end{array}$

or instruction

2. Argues with teachers

about rules or instructions

3. Has difficulty accepting

criticism or correction

4. Does not obey school

rules on his/her own

5. Refuses to obey

until threatened with punishment

6. Gets angry when doesn't get

his/her own way

7. Acts defiant when

told to do something

8. Has temper tantrums

9. Sasses teacher(s)

10. Whines

11. Cries

12. Pouts

13. Yells or screams

14. Hits teacher(s)

15. Is careless with books

and other objects

16. Destroys books

and other objects

17. Steals

18. Lies

Please continue...

Is this a

problem for you? 
How often does this

occur with this student?
Is this a

problem for you?

$\begin{array}{llllllllllll}\text { 19. Makes noises in class } & 1 & 2 & 3 & 4 & 5 & 6 & 7 & \text { Yes } & \text { No }\end{array}$

20. Teases or provokes

$\begin{array}{llllllllllllll}\text { other students } & 1 & 2 & 3 & 4 & 5 & 6 & 7 & \text { Yes } & \text { No }\end{array}$

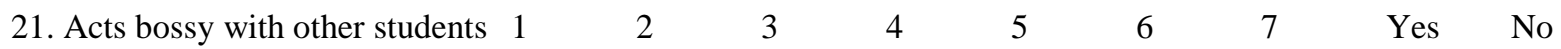

22. Verbally fights with

$\begin{array}{llllllllllll}\text { other students } & 1 & 2 & 3 & 4 & 5 & 6 & 7 & \text { Yes } & \text { No }\end{array}$

23. Physically fights with

other students

24. Demands teacher attention

25. Interrupts teachers

26. Interrupts other students

$\begin{array}{ccccccccc}1 & 2 & 3 & 4 & 5 & 6 & 7 & \text { Yes } & \text { No } \\ 1 & 2 & 3 & 4 & 5 & 6 & 7 & \text { Yes } & \text { No } \\ 1 & 2 & 3 & 4 & 5 & 6 & 7 & \text { Yes } & \text { No } \\ 1 & 2 & 3 & 4 & 5 & 6 & 7 & \text { Yes } & \text { No }\end{array}$

27. Has difficulty entering groups 1

28. Has difficulty sharing materials 1

23

2

29. Is uncooperative in

group activities

12

$\begin{array}{llllll}4 & 5 & 6 & 7 & \text { Yes }\end{array}$

30. Blames others for

problem behaviors

31. Is easily distracted

32. Has difficulty staying on task

$\begin{array}{lllllllll}1 & 2 & 3 & 4 & 5 & 6 & 7 & \text { Yes } & \text { No } \\ 1 & 2 & 3 & 4 & 5 & 6 & 7 & \text { Yes } & \text { No } \\ 1 & 2 & 3 & 4 & 5 & 6 & 7 & \text { Yes } & \text { No }\end{array}$

33. Acts frustrated with

difficult tasks

$\begin{array}{lllllllll}1 & 2 & 3 & 4 & 5 & 6 & 7 & \text { Yes } & \text { No }\end{array}$

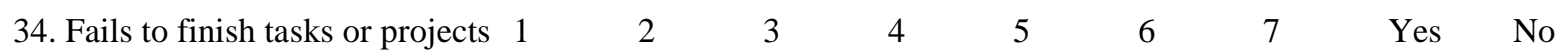

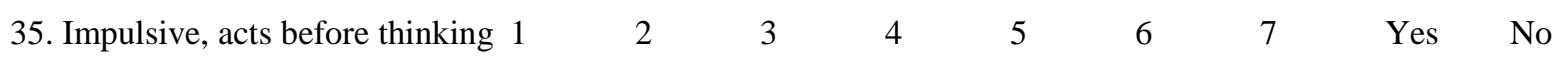

$\begin{array}{llllllllllll}\text { 36. Is over-active or restless } & 1 & 2 & 3 & 4 & 5 & 6 & 7 & \text { Yes } & \text { No }\end{array}$ 


\section{Appendix E}

Teacher Satisfaction Questionnaire

Teacher Name:

Date:

Phase:

Please check the response for each question that best expresses how you honestly feel.

1. Regarding techniques of disciplining, I feel I have learned

_ nothing $\begin{gathered}\text { very little } \\ \text { several useful techniques _ a few new techniques }\end{gathered}$

2. Regarding techniques for teaching children new skills, I feel I have learned nothing very little several useful techniques a few new techniques very many useful techniques

3. Regarding the relationship between myself and the children in the class, I feel we get along much worse than before somewhat worse than before same as before somewhat better than before very much better than before

4. Regarding my confidence in my ability to discipline children in the classroom, I feel much less confident ___ somewhat less confident same as before somewhat more confident much more confident

5. The major behavior problems that occurred in my classroom before the program started are at this time
considerably worse somewhat worse the same

6. I feel that children's compliance to my commands or requests is at this time considerably worse somewhat improved somewhat worse greatly improved the same

7. Regarding the progress children in my class have made in their general behavior, I am very dissatisfied somewhat satisfied somewhat dissatisfied very satisfied neutral

8. How likely are you to recommend this behavior management program to another teacher? not at all a little somewhat pretty likely very

9. I feel the type of program that was used to help me improve the behavior of children in my class was very poor poor __ adequate

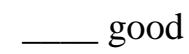
very good

10. My general feeling about the program I participated in is I disliked it very much I disliked it somewhat I liked it somewhat __ I liked it very much I feel neutral 


\section{Appendix F \\ Didactic Integrity Checklist}

The definition of descriptions was given.

An example of the use of a description was provided.

The definition of reflections was given.

An example of the use of a reflection was provided.

The definition of labeled praise was given.

_ An example of the use of a labeled praise was provided.

The definition of criticism given.

An example of a criticism was provided.

The definition of two-choices statement was given.

An example of the use of a two-choices statement was provided.

A definition of the use of timeout was given.

The teachers were given an opportunity to ask questions. 


\section{Appendix G}

\section{Coaching Integrity Checklist}

The following words were used fewer than 3 times during the session: "no," "don't," "stop," "not," "quit."

Feedback generally was concise (i.e., fewer than 10 words per feedback).

The therapist indicated a change in child behavior to the teacher during the coaching session.

Overall, more praise than correction was used.

At least 30 statements were provided during the 30-minute coaching period. More labeled praises than unlabeled praises were used. 
Appendix $\mathrm{H}$

\section{Definitions of Skills}

\section{$\underline{\text { Positive Skills }}$}

Description: Running commentary of the appropriate behaviors in which a child is engaging.

"You put the red marker back in the box. Now you're putting the green marker away."

Reflection: Verbal repetition of a child's utterances.

If the child is driving a car on the table, the parent also would drive a car on the table.

Labeled Praise: Praise that explicitly identifies the behavior that is receiving the parent's approval.

"I like the way you are sitting at the table."

"Thank you for putting the toys away gently."

\section{Discipline Skills}

Effective Command: Statement that clearly and directly states the requested behavior.

"Please sit in your chair."

"Bethany, please put the train on the table."

Two-Choices Statement: Statement that specifies the two response options from which the child has to choose (e.g., compliance or timeout).

"You have two choices. You can either put the block in the box or you can go to timeout."

Timeout: A period of time during which the child receives no social interaction, has no stimulating activities, and sits alone in a designated place. Timeout can be conducted using a timeout chair, a timeout space, or a timeout room. 
Appendix I

Behavior Management Training

“Do" Skills

\begin{tabular}{|c|c|c|}
\hline Rule & Reason & Examples \\
\hline $\begin{array}{l}\text { Do DESCRIBE } \\
\text { appropriate behavior. }\end{array}$ & $\begin{array}{l}\text { Allows child to lead } \\
\text { Shows child you're interested } \\
\text { Teaches concepts } \\
\text { Models speech } \\
\text { Hold's child's attention } \\
\text { Organizes child's thoughts about } \\
\text { Play }\end{array}$ & $\begin{array}{l}\text { That's a red block. } \\
\text { You're making a tower. } \\
\text { You drew a smiling face. } \\
\text { The cowboy looks happy. }\end{array}$ \\
\hline $\begin{array}{l}\text { Do REFLECT } \\
\text { appropriate talk. }\end{array}$ & $\begin{array}{l}\text { Doesn't control the conversation } \\
\text { Shows child you're really listening } \\
\text { Demonstrates acceptance and } \\
\text { Understanding } \\
\text { Improves child's speech } \\
\text { Increases verbal communication }\end{array}$ & $\begin{array}{l}\text { Child: I made a star. } \\
\text { Teacher: Yes, you made a star. } \\
\text { Child: The camel got bumps } \\
\text { on top. } \\
\text { Teacher: It has two humps on } \\
\text { its back. } \\
\text { Child: I like to play with this } \\
\text { castle. } \\
\text { Teacher: This is a fun castle } \\
\text { to play with. }\end{array}$ \\
\hline $\begin{array}{l}\text { Do PRAISE appropriate } \\
\text { behavior. }\end{array}$ & $\begin{array}{l}\text { Causes the behavior to increase } \\
\text { Lets child know what you like } \\
\text { Increases self-esteem } \\
\text { Adds to warmth of the relationship } \\
\text { Makes both teacher and child feel } \\
\text { good! }\end{array}$ & $\begin{array}{l}\text { Terrific counting! } \\
\text { I like the way you're playing } \\
\text { so quietly. } \\
\text { You have wonderful ideas for } \\
\text { this game. } \\
\text { I'm proud of you for being } \\
\text { polite. } \\
\text { You did a nice job on that } \\
\text { building. } \\
\text { Your design is pretty. } \\
\text { Thank you for showing the } \\
\text { colors to me. }\end{array}$ \\
\hline
\end{tabular}


"Don't" Skills

\begin{tabular}{|l|l|l|}
\hline Careful with commands. & $\begin{array}{l}\text { See Giving Good Directions } \\
\text { handout }\end{array}$ & $\begin{array}{l}\text { Indirect: } \\
\text { Will you hand me that paper? } \\
\text { Could you tell me the } \\
\text { alphabet? } \\
\text { Direct: }\end{array}$ \\
& $\begin{array}{l}\text { Look at this. } \\
\text { Please tie your shoe. } \\
\text { Come here. }\end{array}$ \\
\hline Don't ask questions. & $\begin{array}{l}\text { Leads the conversation instead of } \\
\text { following. } \\
\text { Many are commands or require an } \\
\text { answer } \\
\text { May seem like you aren't listening } \\
\text { or disagree with child }\end{array}$ & $\begin{array}{l}\text { That's a blue one, right? } \\
\text { What color is this? } \\
\text { Are you having fun? } \\
\text { You want to play with the } \\
\text { wastebasket? }\end{array}$ \\
& $\begin{array}{l}\text { Doesn't work to decrease bad } \\
\text { Behaviors } \\
\text { Often increases the criticized } \\
\text { Behavior } \\
\text { May lower the child's self-esteem } \\
\text { Creates an unpleasant interaction }\end{array}$ & $\begin{array}{l}\text { You're being naughty. } \\
\text { I don't like it when you talk } \\
\text { back. } \\
\text { Don't scribble on your paper. } \\
\text { No, that's not right. } \\
\text { That design is ugly. }\end{array}$ \\
\hline
\end{tabular}




\section{Appendix J}

\section{Giving Good Directions}

\begin{tabular}{|c|c|c|}
\hline Rule & Reason & Examples \\
\hline $\begin{array}{l}\text { Make commands direct, } \\
\text { not indirect. }\end{array}$ & $\begin{array}{l}\text { Eliminates any ambiguity about } \\
\text { whether teacher expects child } \\
\text { to obey } \\
\text { Makes it clear the child, not the } \\
\text { teacher, is to do the task }\end{array}$ & $\begin{array}{l}\text { Direct: Sit down right here. } \\
\text { Indirect: Would you like to sit } \\
\quad \text { down? } \\
\text { Direct: Pick up your toys. } \\
\text { Indirect: Let's pick up your } \\
\text { toys, okay? }\end{array}$ \\
\hline $\begin{array}{l}\text { Make commands single } \\
\text { and small, not compound. }\end{array}$ & $\begin{array}{l}\text { Easier for child to obey smaller } \\
\text { commands that are not } \\
\text { overwhelming } \\
\text { Some children can't remember } \\
\text { multiple-part commands } \\
\text { The child gets more } \\
\text { opportunities for praise }\end{array}$ & $\begin{array}{l}\text { Put the Legos on the shelf. } \\
\text { (instead of...Clean up the } \\
\text { play area.) } \\
\text { Put the paintbrush in the sink. } \\
\text { Hang up your smock. Wash } \\
\text { your hands. (instead } \\
\text { of...Clean up the art table.) }\end{array}$ \\
\hline $\begin{array}{l}\text { State commands positively } \\
\text { (tell child what to do, } \\
\text { instead of what not to do). }\end{array}$ & $\begin{array}{l}\text { Oppositional children rebel } \\
\text { against "stop" and "don't" } \\
\text { commands } \\
\text { Tells child what (s)he can do } \\
\text { instead. }\end{array}$ & $\begin{array}{l}\text { Child: (on counter) } \\
\text { Teacher: Get down please. } \\
\text { (instead of...Don't climb on } \\
\text { the counter!) } \\
\text { C: (bouncing ball indoors) } \\
\text { Teacher: Please get a book to } \\
\text { read. (instead of...Stop } \\
\text { bouncing that ball!) } \\
\text { C: (runs away from teacher) } \\
\text { T: Hold my hand. (instead } \\
\text { of...Don't run away from } \\
\text { me!) }\end{array}$ \\
\hline $\begin{array}{l}\text { Make commands specific, } \\
\text { not vague. }\end{array}$ & $\begin{array}{l}\text { Let's child know exactly what is } \\
\text { expected } \\
\text { Eliminates confusion } \\
\text { Makes it easier to decide } \\
\quad \text { whether child has obeyed }\end{array}$ & $\begin{array}{l}\text { Use your indoor voice (instead } \\
\text { of...Act nice!) } \\
\text { Please walk (instead } \\
\text { of...Behave yourself.) } \\
\text { Wait for your turn. (instead } \\
\text { of...Play nicely.) }\end{array}$ \\
\hline $\begin{array}{l}\text { Use a neutral tone of } \\
\text { voice, instead of pleading } \\
\text { or yelling. }\end{array}$ & $\begin{array}{l}\text { Children need to learn to } \\
\text { respond to commands given in } \\
\text { a normal, conversational voice } \\
\text { Makes interactions more } \\
\text { pleasant for both child and } \\
\text { parent }\end{array}$ & $\begin{array}{l}\text { Come sit next to me. (instead } \\
\text { of...Sit here now!! or It } \\
\text { would really make me happy } \\
\text { if you would sit here, } \\
\text { please?!) }\end{array}$ \\
\hline $\begin{array}{l}\text { Be polite and respectful, } \\
\text { while still being direct. }\end{array}$ & $\begin{array}{l}\text { Makes interactions more } \\
\text { pleasant } \\
\text { Models good social skills } \\
\text { Less likely to cause an } \\
\text { oppositional child to disobey. }\end{array}$ & $\begin{array}{l}\text { Please hand me the crayon. } \\
\text { Sit next to me please. }\end{array}$ \\
\hline
\end{tabular}




\begin{tabular}{|c|c|c|}
\hline $\begin{array}{l}\text { Save direct commands for } \\
\text { things you're sure the } \\
\text { child can do. }\end{array}$ & $\begin{array}{l}\text { It's unfair to punish } \\
\text { disobedience if the child was } \\
\text { unable to obey } \\
\text { To encourage a child to try } \\
\text { something new, use an } \\
\text { indirect command or } \\
\text { suggestion, instead of a direct } \\
\text { command }\end{array}$ & $\begin{array}{l}\text { Make a picture. (instead } \\
\text { of...Draw a stop sign) } \\
\text { Would you like to try to sign it? } \\
\text { (instead of... Write your } \\
\text { name) }\end{array}$ \\
\hline $\begin{array}{l}\text { Don't give too many } \\
\text { direct commands }\end{array}$ & $\begin{array}{l}\text { Neither adults nor children like } \\
\text { to be told what to do } \\
\text { constantly } \\
\text { It is hard to follow through with } \\
\text { consequences each time if too } \\
\text { many commands are given }\end{array}$ & \\
\hline $\begin{array}{l}\text { Always provide a } \\
\text { consequence for } \\
\text { obedience and } \\
\text { disobedience }\end{array}$ & $\begin{array}{l}\text { Fastest way to teach young } \\
\text { children to mind better } \\
\text { Compliance should not be taken } \\
\text { for granted } \\
\text { Consistency in providing } \\
\text { consequences is the most } \\
\text { powerful tool for improving } \\
\text { child behavior }\end{array}$ & $\begin{array}{l}\text { Teacher: Hand me your paper. } \\
\text { Child: (hands paper to teacher) } \\
\text { T: Thanks for doing what I } \\
\text { asked! You're a good helper. } \\
\text { C: (fails to hand paper to } \\
\text { parent) } \\
\text { T: You have two choices. You } \\
\text { can hand me your paper or sit } \\
\text { in time-out }\end{array}$ \\
\hline $\begin{array}{l}\text { Use choice commands } \\
\text { with older preschoolers. }\end{array}$ & $\begin{array}{l}\text { Encourages the development of } \\
\text { autonomy and decision- } \\
\text { making } \\
\text { Doesn't take the "power" away } \\
\text { from a child who tends to get } \\
\text { in power struggles }\end{array}$ & $\begin{array}{l}\text { Please read a book or color } \\
\text { quietly. } \\
\text { Please put on your jacket or } \\
\text { your sweater. }\end{array}$ \\
\hline $\begin{array}{l}\text { Use explanations } \\
\text { sparingly. }\end{array}$ & $\begin{array}{l}\text { Children who ask for } \\
\text { explanations are usually more } \\
\text { interested in stalling than } \\
\text { knowing the answer } \\
\text { Gives child the impression that } \\
\text { he might be able to talk his } \\
\text { way out of it } \\
\text { If used, give explanation before } \\
\text { the command to head off } \\
\text { arguing }\end{array}$ & $\begin{array}{l}\text { Teacher: Put the crayons away. } \\
\text { Child: Why? } \\
\text { T: Because we need to get ready } \\
\text { to go. } \\
\text { C: After I finish. } \\
\text { T: I said put the crayons away } \\
\text { now!! } \\
\text { Better... } \\
\text { T: Playtime is over and we need } \\
\text { to get ready to leave. Please } \\
\text { put your crayons away. } \\
\text { C: Why? } \\
\text { T: (ignores delay tactics because } \\
\text { explanation already has been } \\
\text { given) }\end{array}$ \\
\hline
\end{tabular}




\section{Child Behavior}

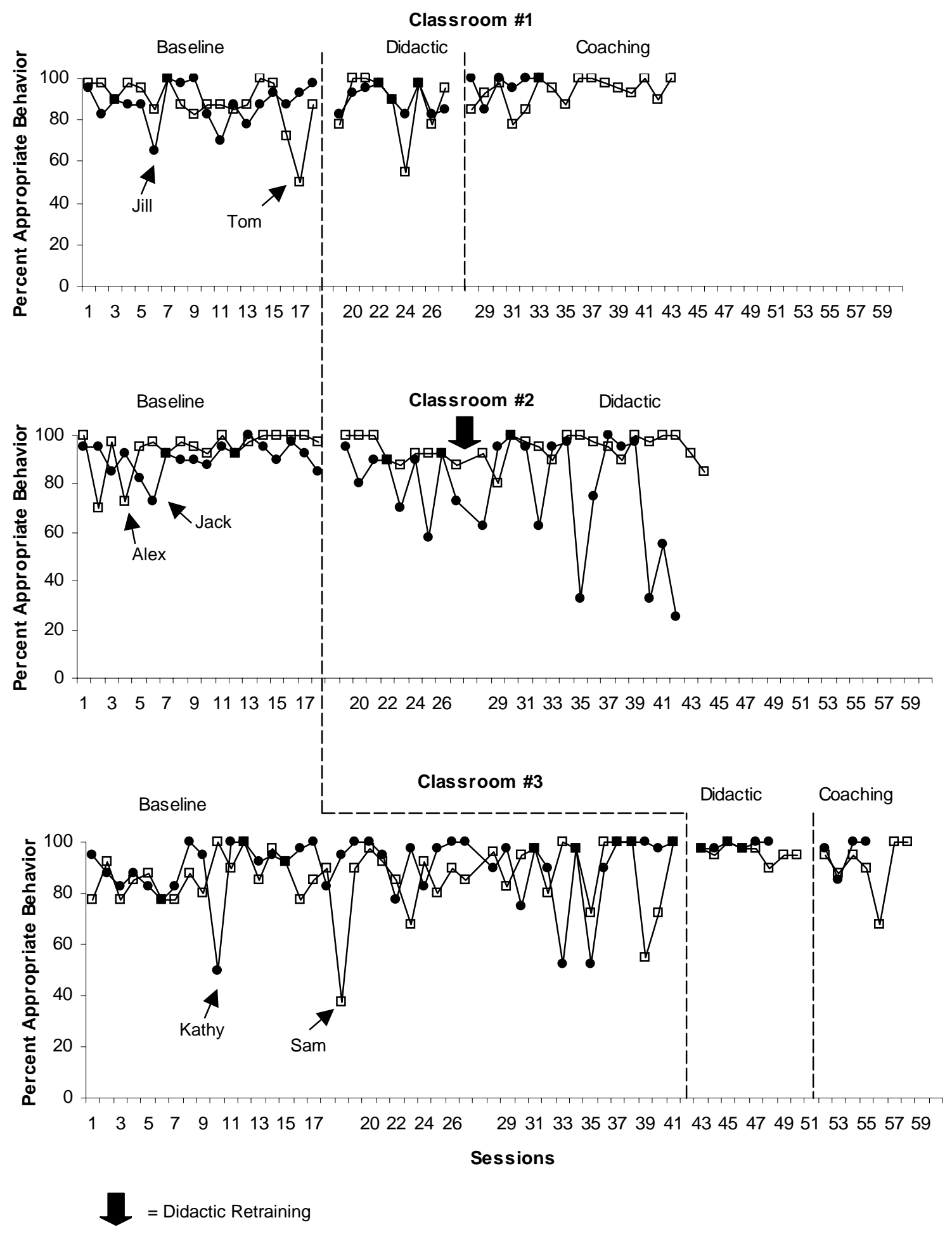




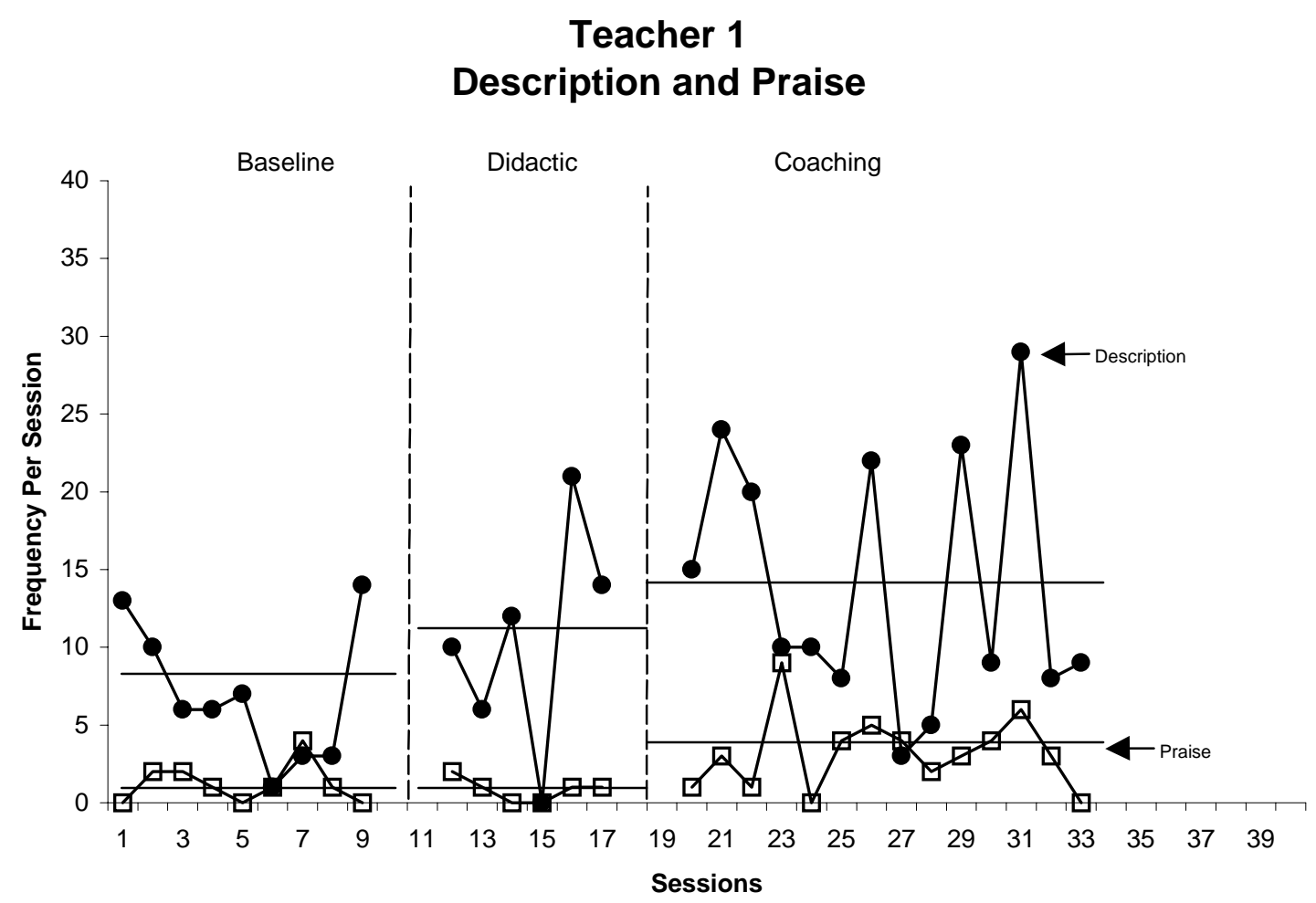

Teacher 1

Question and Criticism

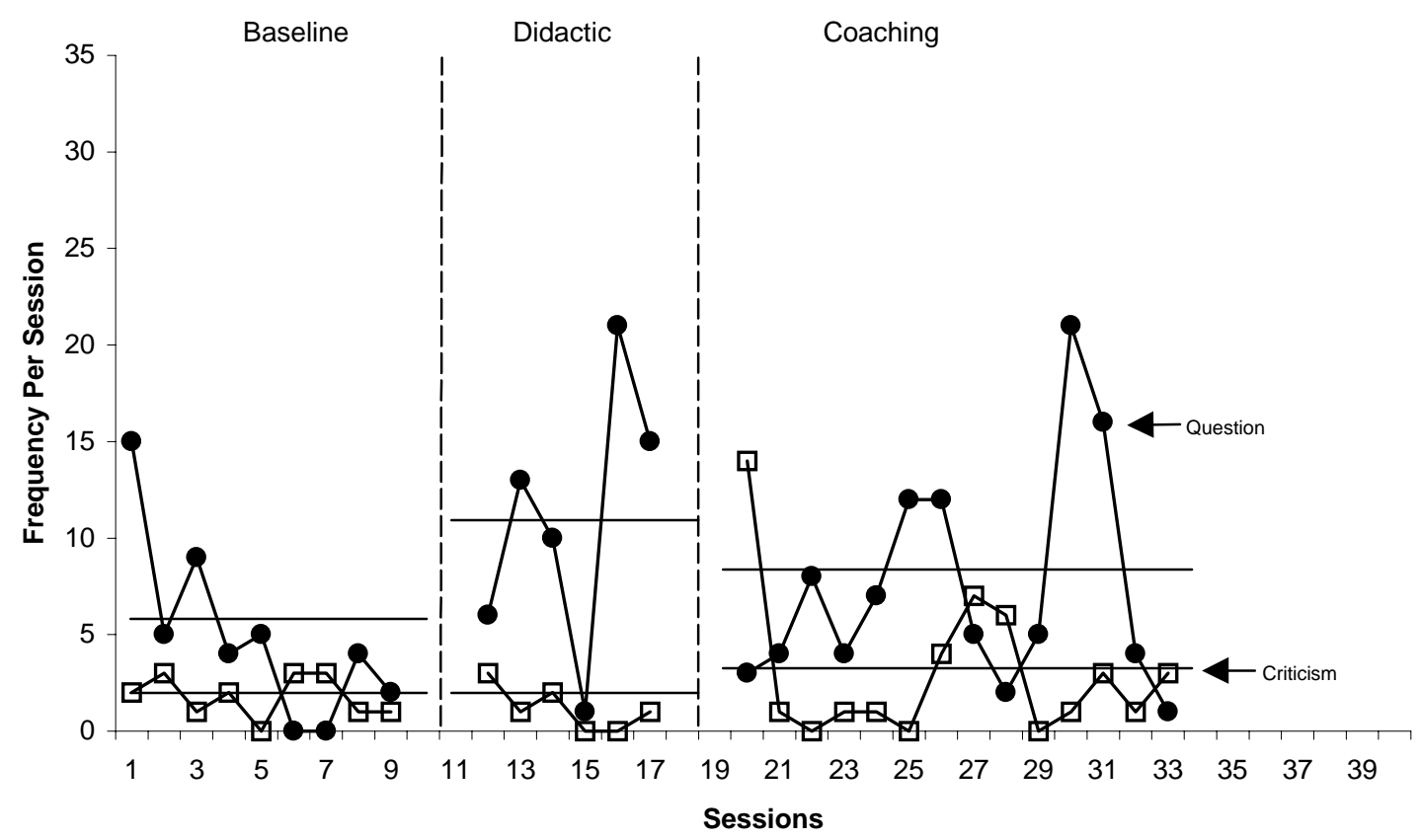


Teacher 2

Description and Praise

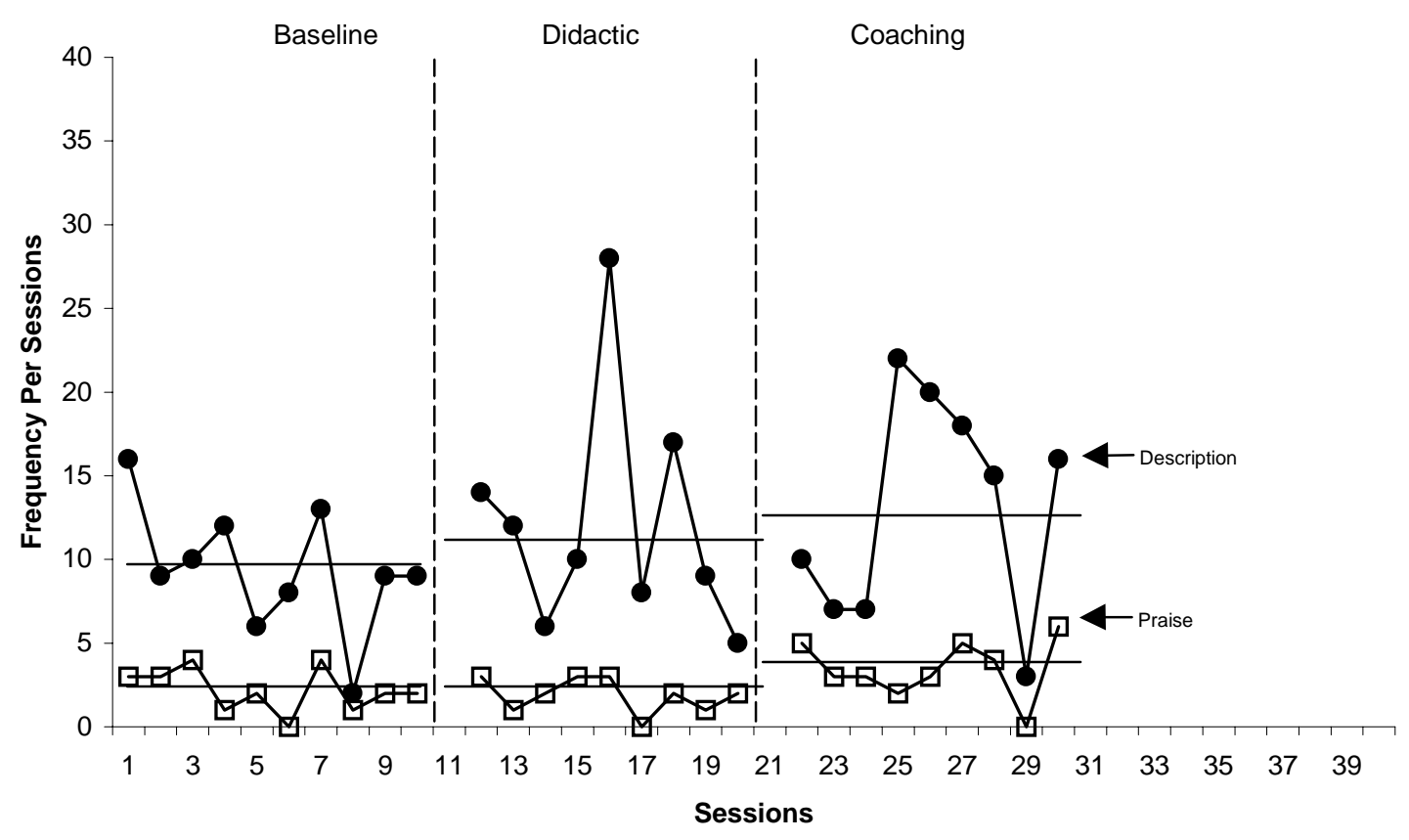

Teacher 2

Question and Criticism

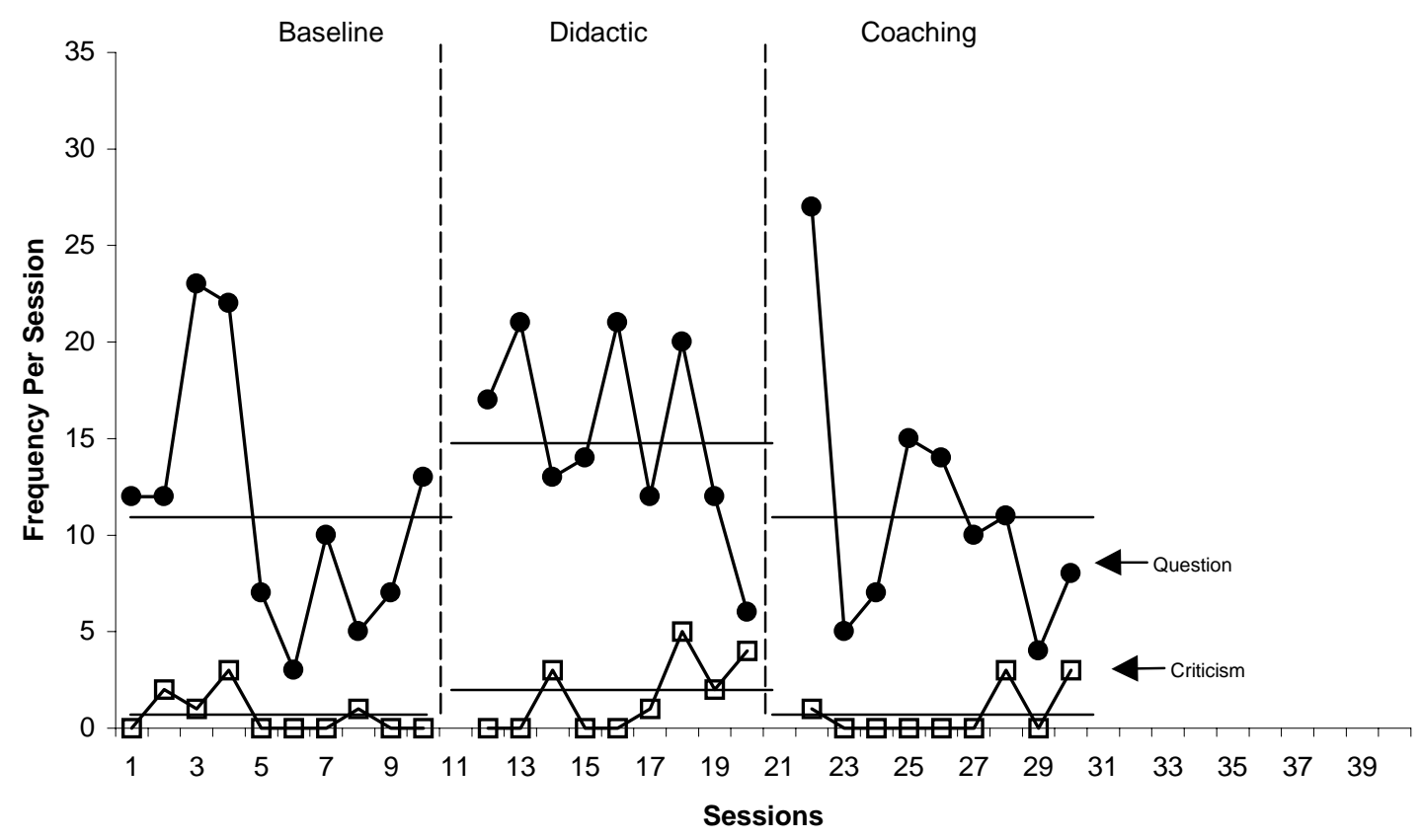


Teacher 1

Command Ratio

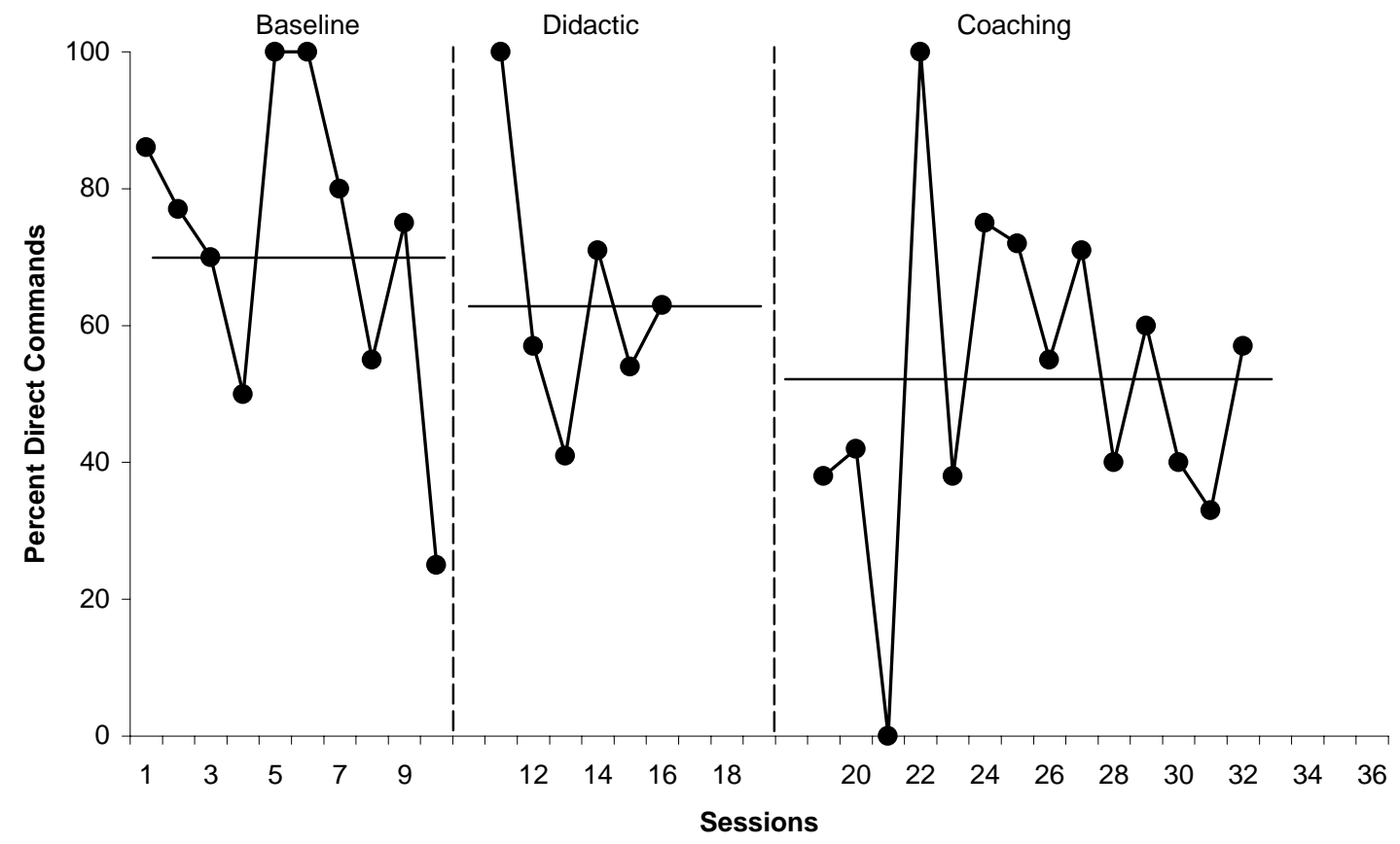

Teacher 2

Command Ratio

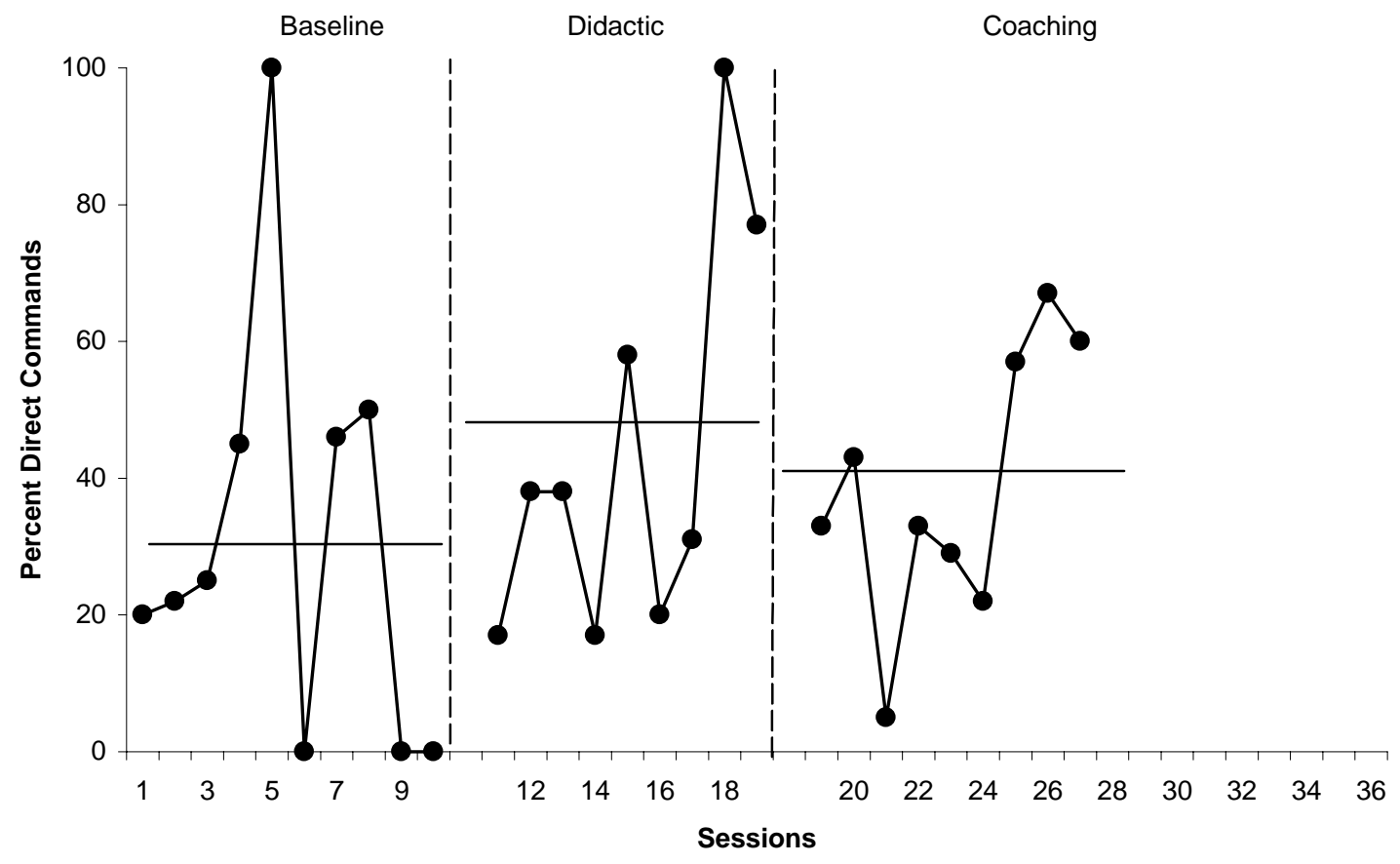


Teacher 3

Description and Praise

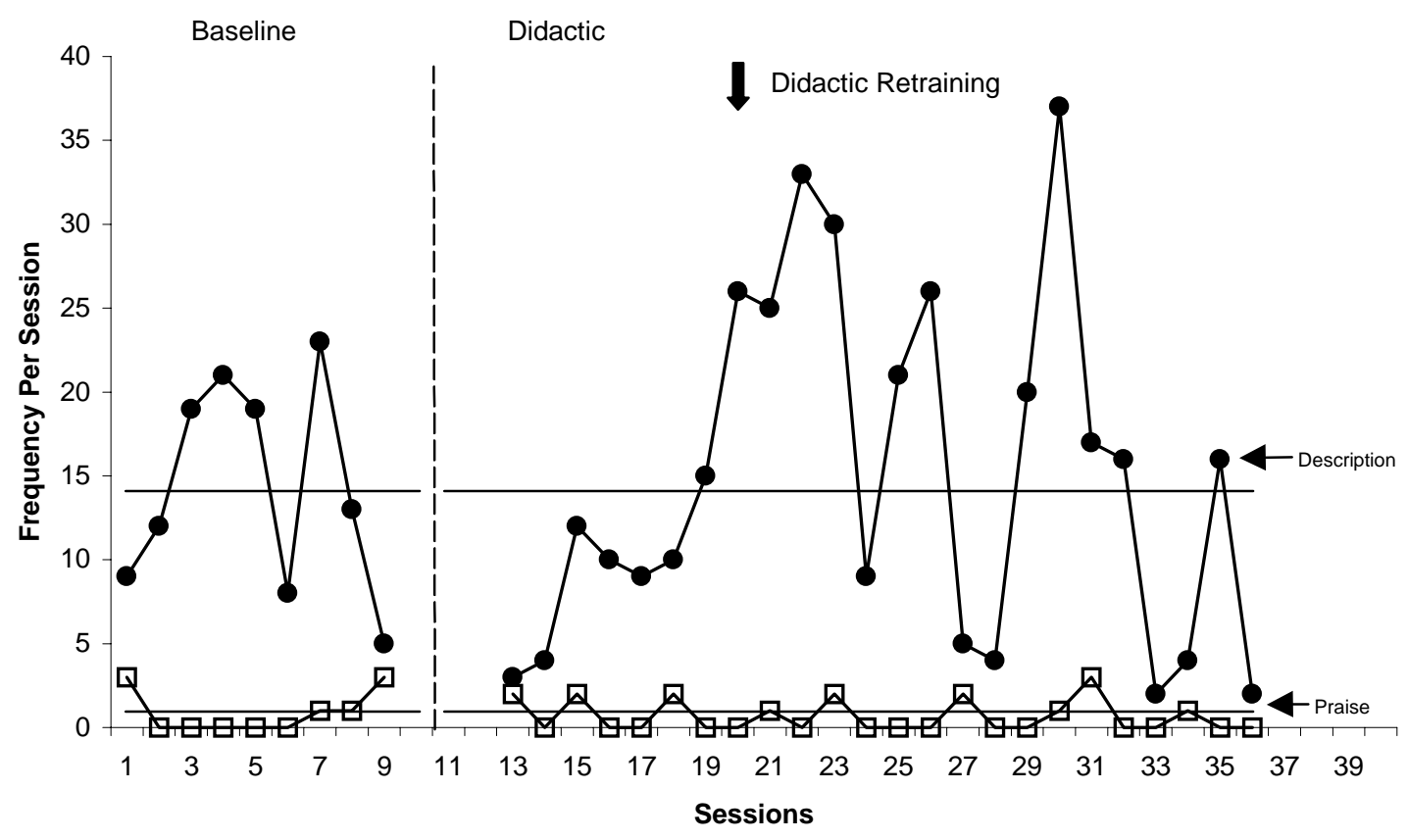

Teacher 3

Question and Criticism

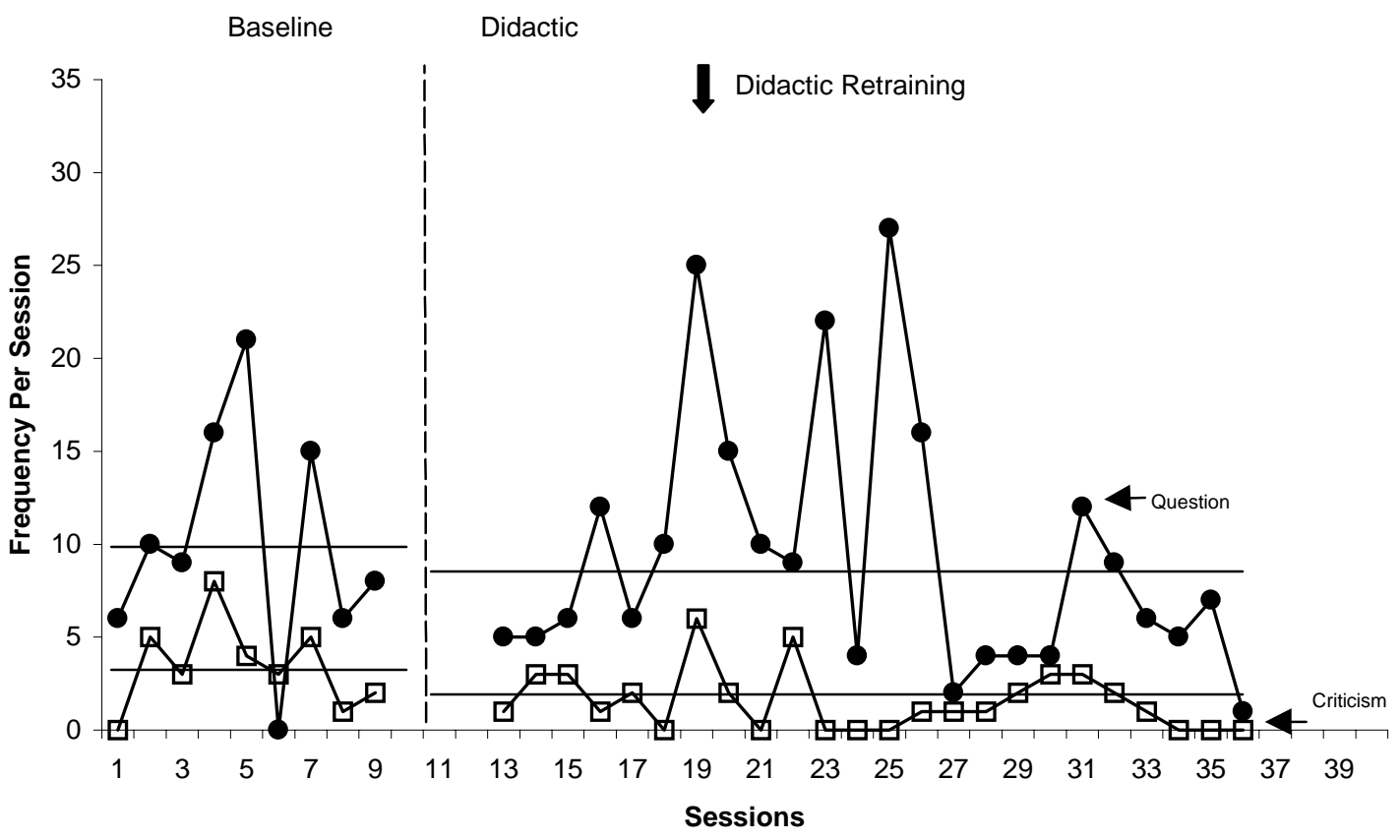




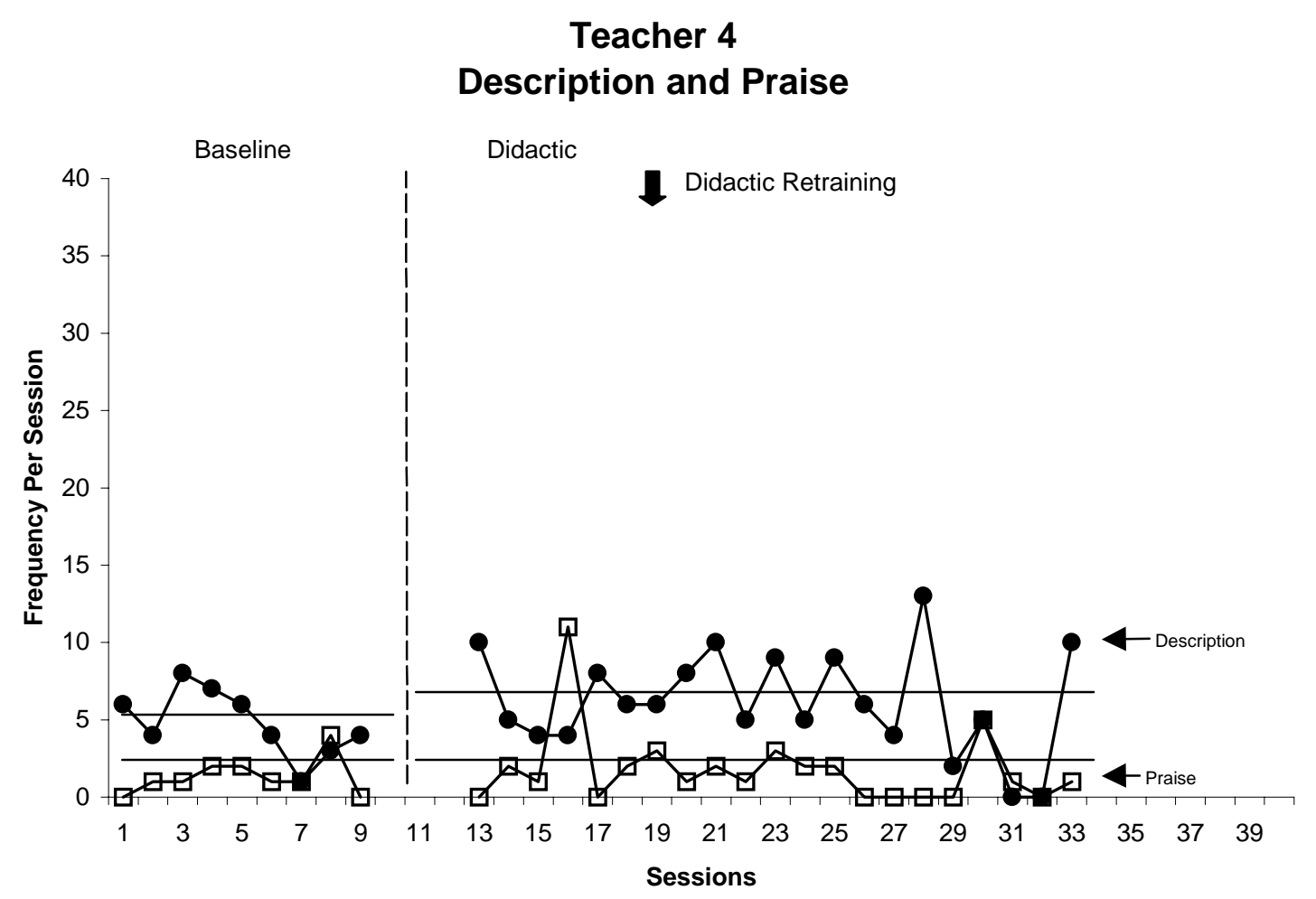

Teacher 4

Question and Criticism

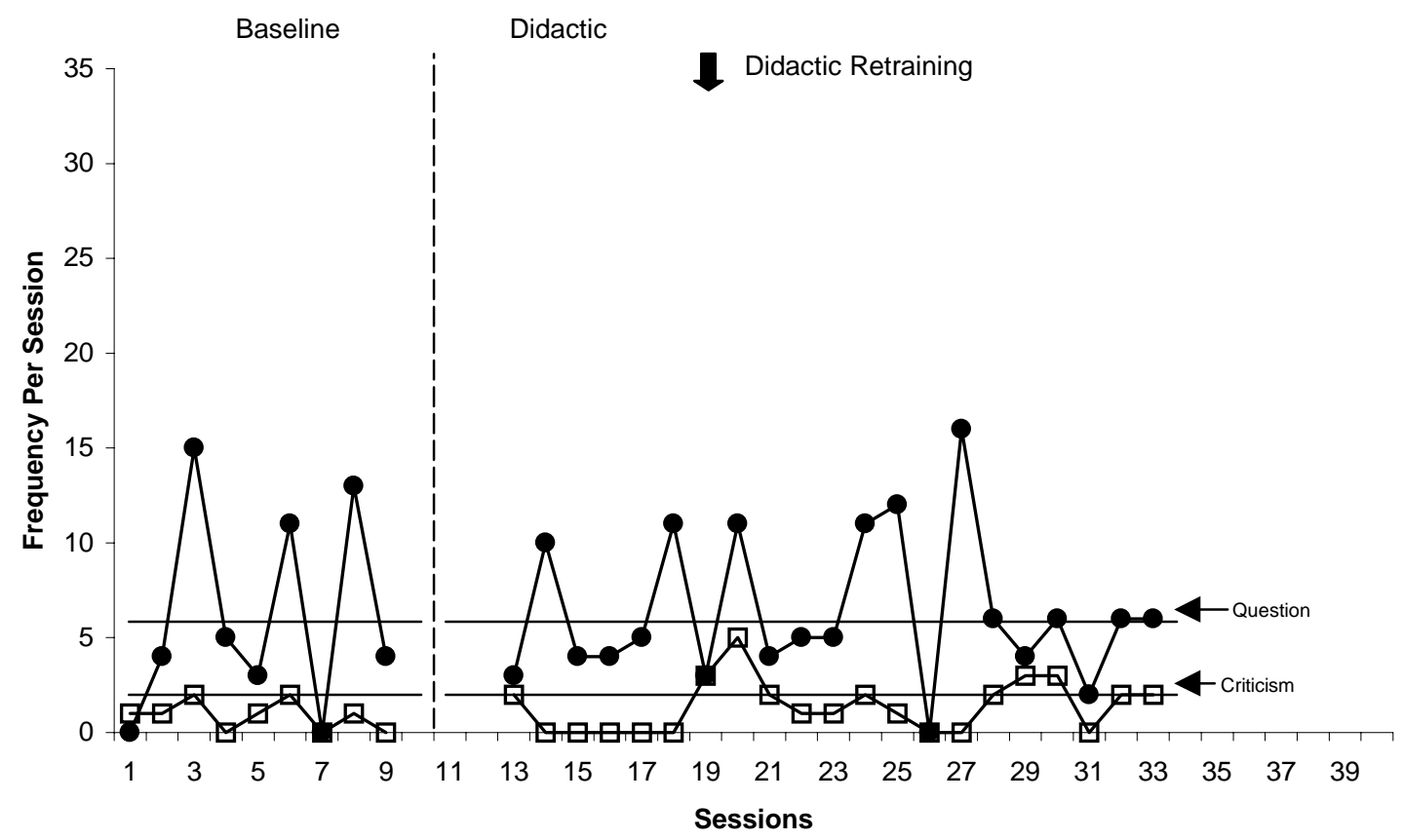


Teacher 3

Command Ratio

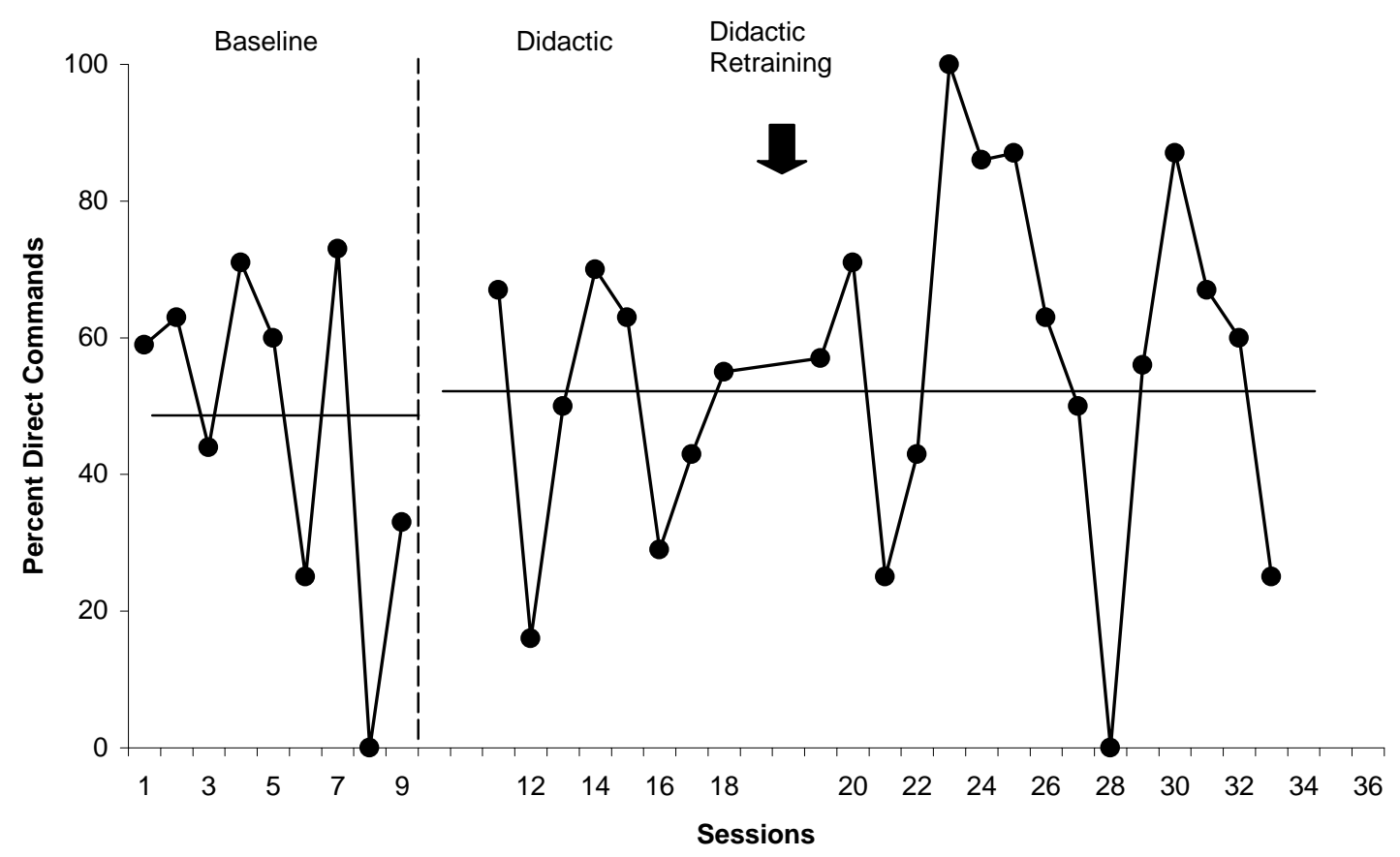

Teacher 4

Command Ratio

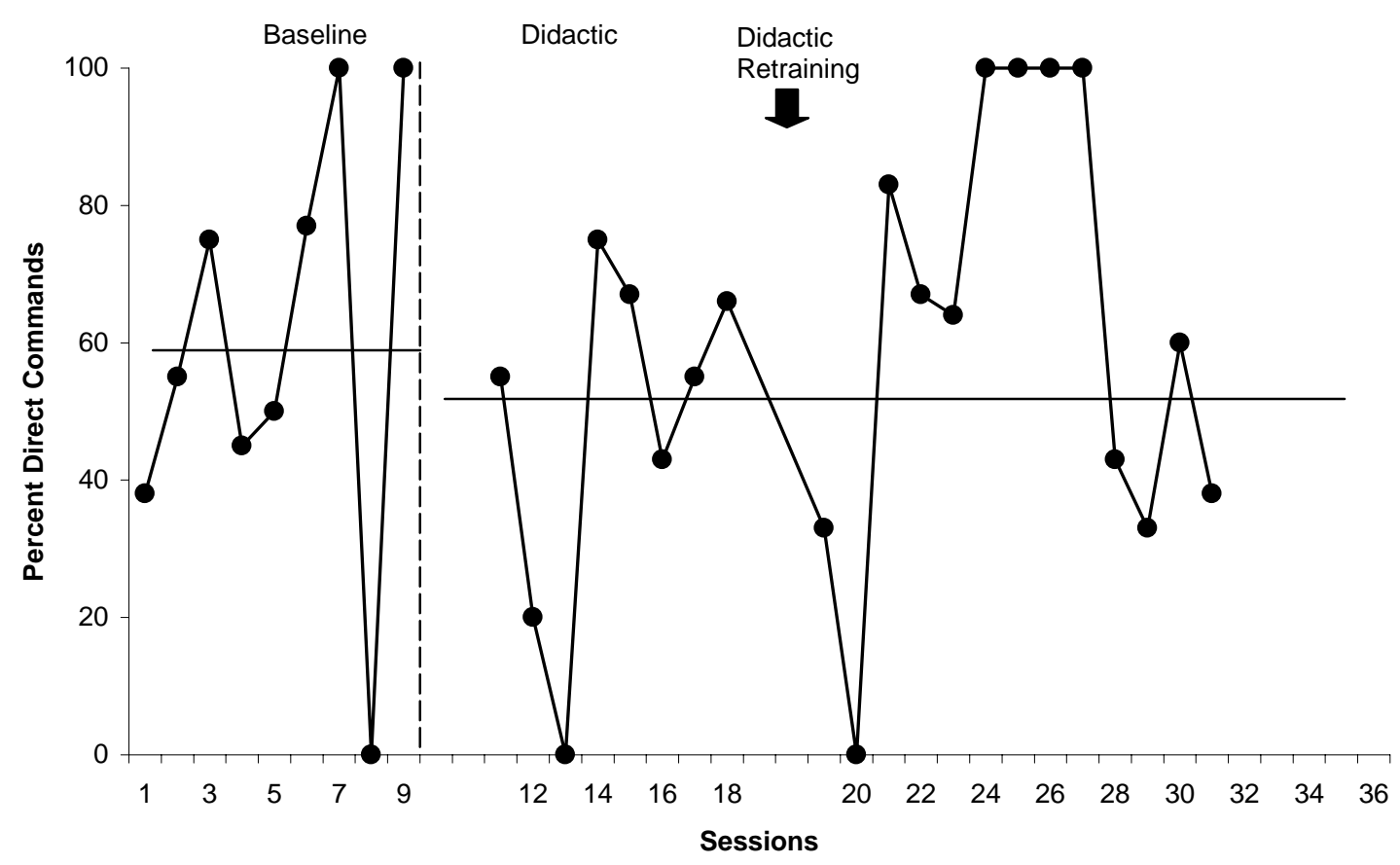


Teacher 5

Description and Praise

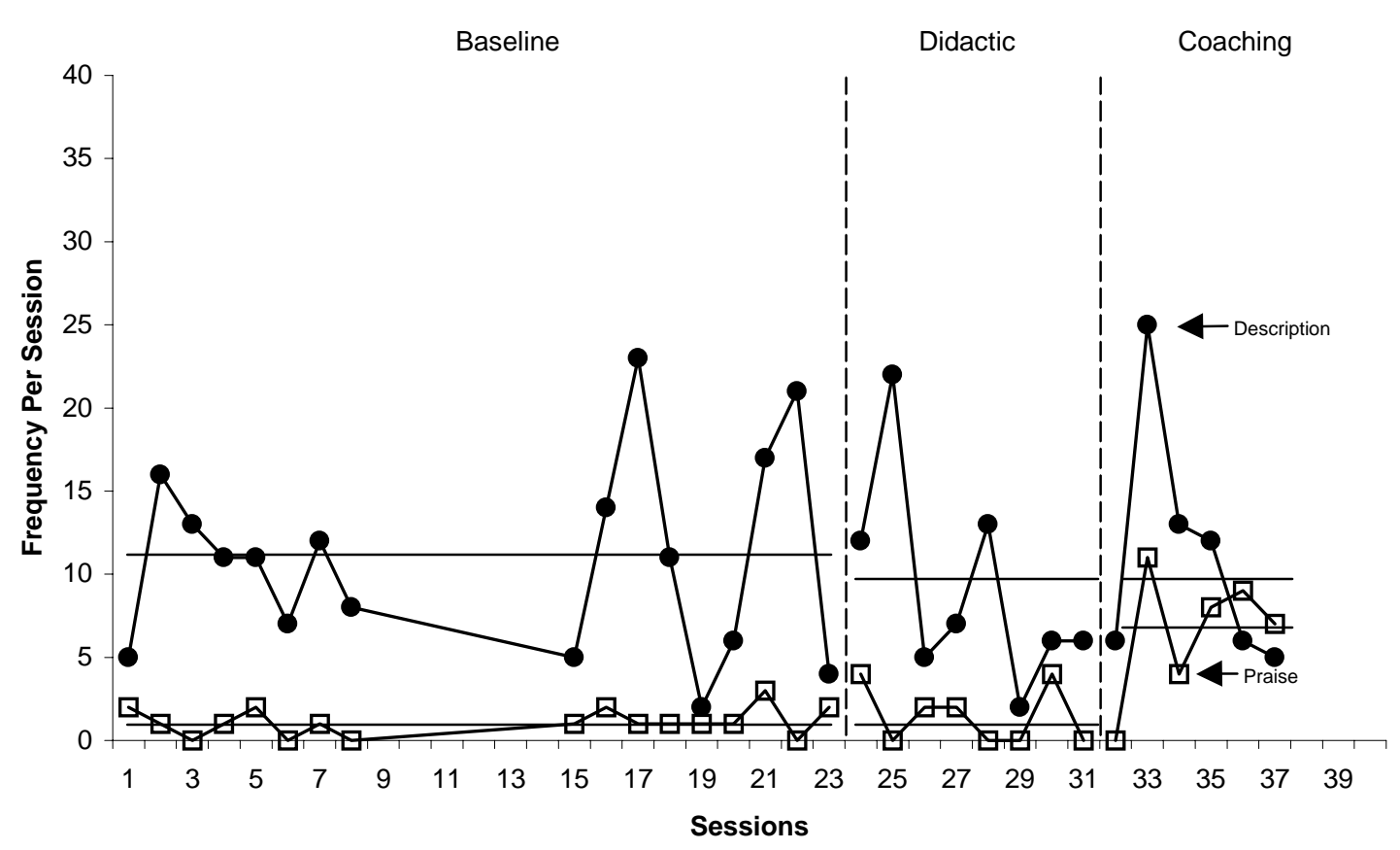

Teacher 5

Question and Criticism

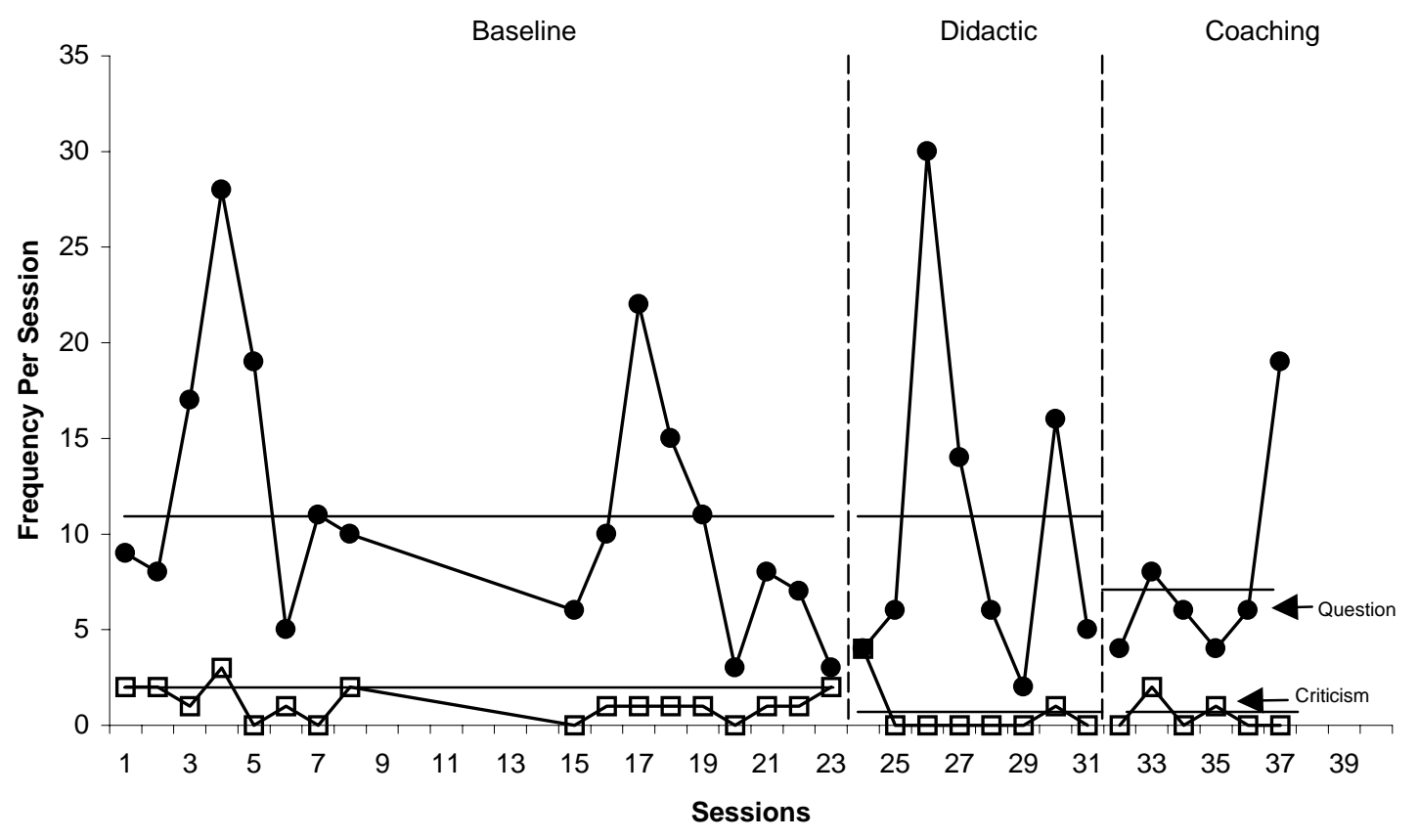


Teacher 6

Description and Praise

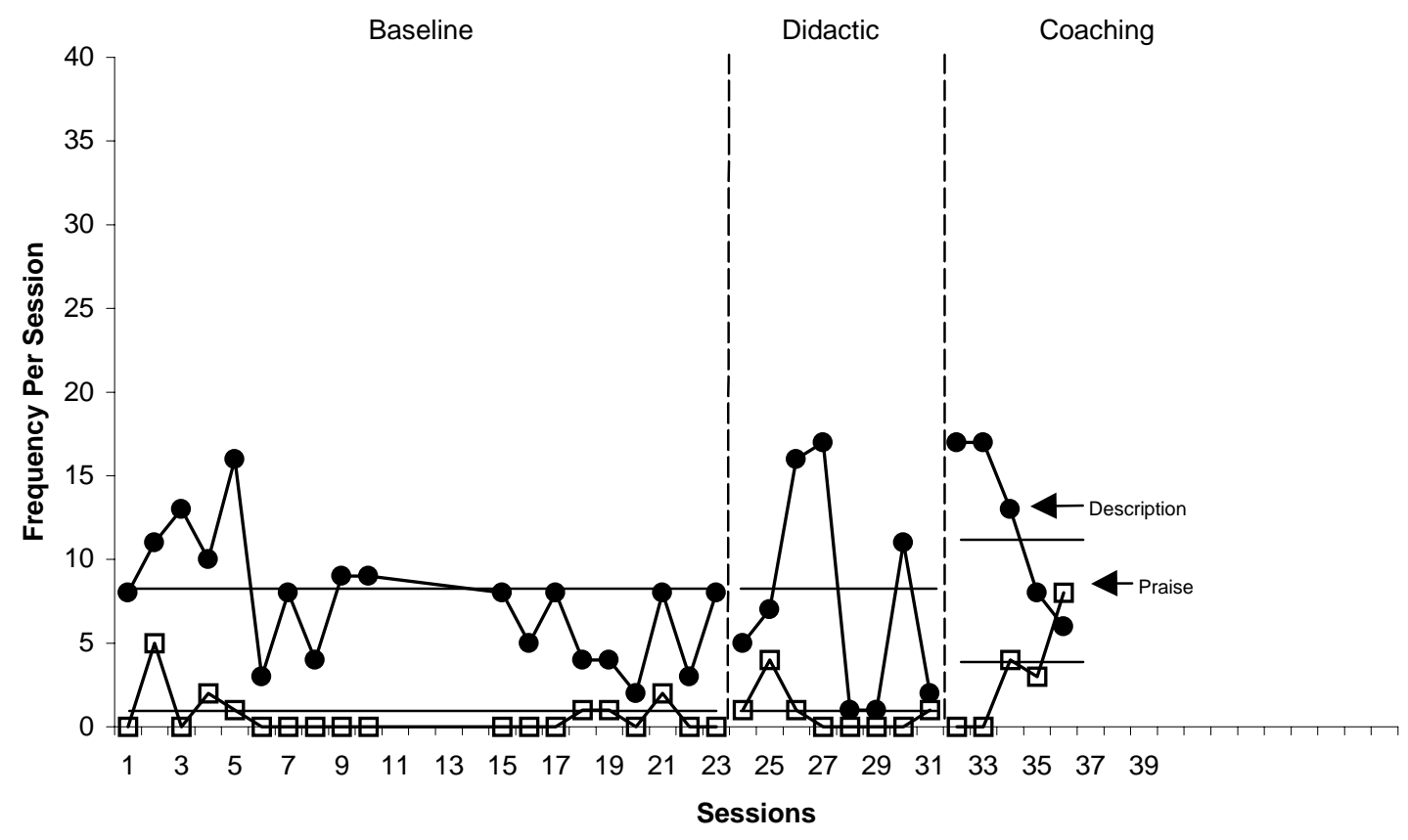

Teacher 6

Question and Criticism

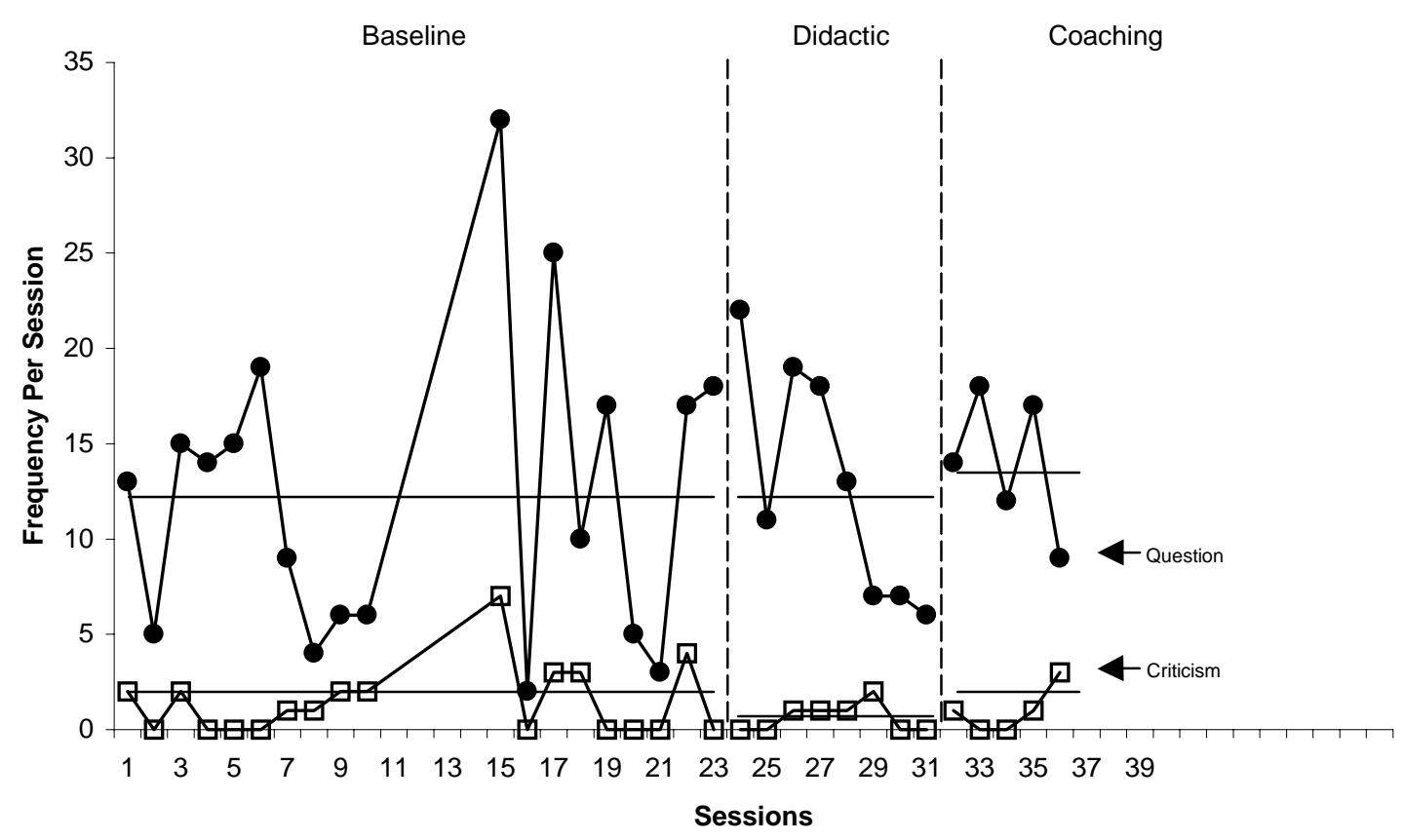


Teacher 5

Command Ratio
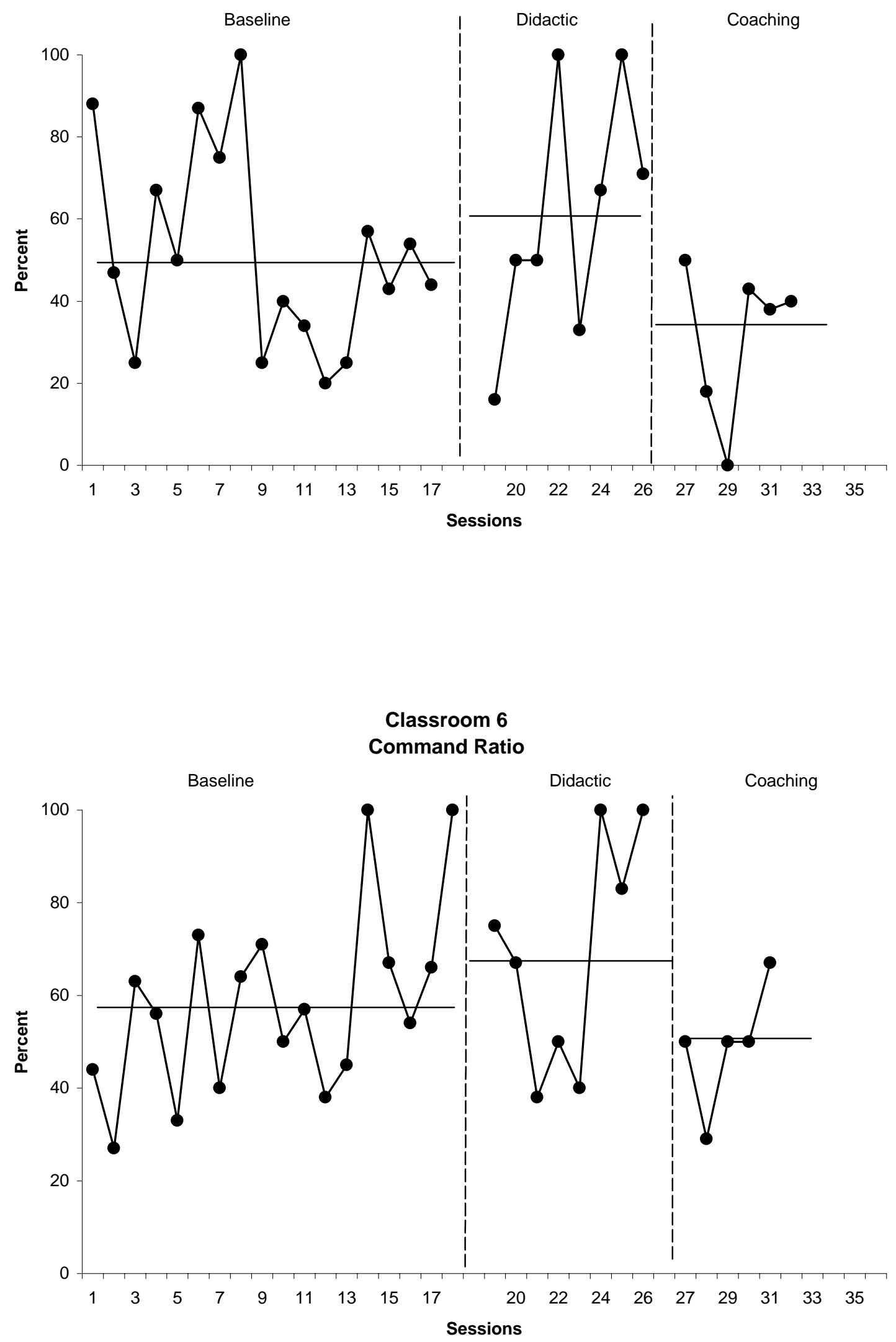